\title{
Generalizing Productivity and Service Stake. A Heterodox Widened Approach
}

\author{
Alexandru JIVAN, Miruna-Lucia NĂCHESCU \\ DOI 10.1515/JHEEC-2017-0005
}

\begin{abstract}
The aim of the present paper is to put together, point out and underline the core characteristics of a generalized concept of productivity built on a heterodox outlook. The analysis is conducted under the assumption that the developing knowledge in nowadays society and the concern for basing the economy on it require a reviewed approach on productivity. Relevant moments from the economic thought and literature are invoked(certain approaches on productivity from the most representative Romanian economic thought here included); the research finds reason and main conceptual grounds in the genuine liberalism and in the service economy, by a critical view on the concern for productivity growth as commonly seen and calculated. The paper also aims to bring to the current attention some pioneer work, less known but very important for the productivity mark. The paper develops the service stake as defining value creation and reveals the most important differences between common productivity (usually calculated productivity) and the new approach that takes into account the generalized service approach consistent with nowadays society.

This paper is a theoretical presentation designed to serve as an improved context for reconsidering the researches focused on - or connected with productivity.
\end{abstract}

Keywords:

JEL Classification: productivity, service economy, knowledge society, value creation A19, L80.

\section{Introduction}

With industrialization, productivity started an unprecedented acceleration, and the concern for its matter increased (both in practice and in economic theory analyses at diverse levels). This concern persists in nowadays: there is almost no economic data analysis that does not, in one way or another, make references to some aspects of 
productivity. Increased productivity has brought improvements in the efficiency of using economic factors, ever-increasing outputs, increasing the wealth of mankind, opulence ... However, as we broaden the horizon of concerns, today we cannot ignore the effects other than and different from those targeted by the activities/actions of the entities concerned with productivity gains. The "external" effects have to be included in the economic analysis.

The importance of the topic we are interested in this paper is brought by the fact that the concern of enterprisers for productivity (the way such concern was managed) lets or even generates important environmental problems and new challenges to accompany market success. By reaching a stage superior to industrialization and to the rather quantitative concerns, i.e. by paying attention rather to the qualitative dimensions of economic life, the knowledge society must re-orientate economic research to more wide and detailed manner of approaching productivity.

The purpose of the paper is revealing main elements of the ways of understanding and approaching the quality trait of producing/creating value, including else than the most usual ones.

Aiming at better showing the differences between the common approach of productivity and the widening of horizons that we proposed in this matter, most important routs, theoretical grounds, basic principles and features are presented.

Our paper puts under question a few elements that fundament a debate on the value and on its generation, showing an opening to new researches and better understanding the economy inside nowadays knowledge society. Our research presents a manner of approaching value productivity that is alternative to the common way understanding and of calculating it.

The literature dealing with productivity topics is extremely rich, both in economics and (mainly) in business research fields, with very diverse goals, most of them presenting and analysing facts, aiming at productivity growth, at diverse levels, distinguishing a large variety of forms and nuances that are related to productivity (like efficiency, effectiveness, performance) ... Our paper is not concerned with such goals, making no data analysis. In this paper we also do not discuss the usual formula that is commonly found in the calculation of productivity, and that actually represents the expression of the common working definition of the concept of productivity (even if the rapport between the output of the entity and the factor input concerned for it is, after all, a starting point of our research). Nuances and concrete variants of such formula may exist in diverse researches, but exactly an approach that is apart from it is in our concern in this paper: we are interested just in grounding an alternative way of approaching the quality of producing value, distinct from the most usual productivity. Therefore, the literature that would suggest the level of research where from we can go further with our research, according to our approach (i.e. the literature that could be beneficially employed in our research) should bring contributions that are consistent rather with other ways of approach than with the most usual manners of approach. In order to fulfil the aims of our research, we rather invoke certain conceptions from the genuine liberalism (concerning value 
production - explanations and literature references in section no. 2) and certain main contributions from the service economy (the section no. 3). But certain references to that what we consider having relevance for our approach are also made from the thought of Mihail Manoilescu and Nicholas Georgescu-Roegen (see sections no. 3 and 4). Our paper is concerned with the economic entity's inner (profound) productivity itself, inner productivity that is not always captured in the standard calculated indicator of productivity.

The grounds and roots of the general service theory are revealed (see section no 1) from the genuine liberalism (main roots being pointed out from the Physiocrat and Classic approach on value production/creation) and from the service economics (starting with Bastiat and certain other ideas taken from the service economy literature). In such building of the reviewed approach, a few basic elements are highlighted, taking into consideration their pioneering contribution. These are fundaments that were enabled by Bastiat, and contributions given also by the Romanian economic literature, contributions that were written in Romanian, English or French and were published under circumstances that didn't ensure the most adequate visibility. We strongly feel that these contributions deserve more attention and should have a stronger impact in the field of the scientific concern for the issue of value production/creation.

The need for changing economic indicators is implicit, as frame for improving the capturing of reality in a more complex approach, appropriate for the growing complexity of the reality and as an alternative to the common propensity to quantities growth, to growth of incomes (engrossing) from the environment - be it economic environment and natural environment as well, with social effects too.

In fulfilling this purpose, previous researches are employed and a synthesis concerning certain moments from the economic thought and several ideas and developments from the more recent literature is designed. The generalised service concept is thus grounded and presented.

With respect to the scientific background of our paper, the references are considered in the next sections, each for its suitable section, appropriately to grounding the ideas, depictions and developments in that sections. The nature of our paper does not recommend a centralized presentation, in the introduction, of the diverse background of our debate and proposals, (together, as an inventory of a such specific literature): in presenting our concern for alternative settings that could widen the usual productivity analyses, most of the literature that we employed or referred to, is quoted in the next sections, i.e. references suitable for dealing with the ideas and topic of each of those sections.

Namely, in section no. 1 we generally refer to the topic of knowledge society, in section no. 2 just certain elements from Quesnay, Smith and other classics are quoted, and in sections no. 3, 4 and 5 references are made to relevant contributions from the literature concerning services and the service economy. Given that the topic of the present research is complex and the topics of those proposals have many sides to be treated, the problems 
of different sections and ways (variants) of conceiving completions or corrections for assessing productivity are varied and, most often, not very unitary.

Under the new circumstances of the economic developments and of the knowledge society (shown under section no.1), the common indicator and approach on productivity can and deserves to be revised. Resorting to bringing to the current attention certain conceptions that are defining for the genuine liberalism (as developed in section no. 2) and invoking as well certain contributions brought by the service economy (section no. 3), a more general way of understanding the special quality trait of creating (producing) value can be designed. Thus, starting from the conceptual ground shown mostly in sections no. 1, 2 and 3, certain attempts, debates and proposals we catalogued for the present paper. They are developed mainly in the sections no. 4 and 5, as the way alternative to the common productivity, aiming at better focusing the economic research on the genuine inner productivity of the economic entity: i.e. in the servicity approach, it means increasing the complexity of the perception on productivity and on its analysis, in more elaborate, wider forms.

In that what concerns the design of the paper, being a theoretical one, the topic is approached by theoretical analysis and conceptual development. No empirical data are presented or analysed, no practice applied issues are shown, and no applying methods are employed. Our research uses no quantitative methods, but just employs certain sources and the suggestions they could contain for designing the servicity approach (Jivan, 1993, 2014), as intrinsic genuine and generalized productivity (alternative to the commonly calculated productivity). Such renewing way, approached in a wider view than the most usual, is presented.

Previous researches are employed in systematization and developments that bring a complex presentation of the ideas, presentation and ideas that will be synthetically found, at the end, in a table comparatively including common productivity and the alternative to it, consistent with nowadays service society based on knowledge. In section no. 5 we present a parallel 'productivity - servicity', explaining the main elements that can frame and define value production and certain related aspects.

\section{Short considerations about the knowledge society as}

\section{context}

The economy and the society as a whole have grown (and are continuously growing) in size and diversity in many aspects, including social relations, financing circuits and trading systems, production processes (increasingly in collaboration and co-production) and outputs, and customer requirements. Flexibility and increased concern for the customer attention (serving) became a rule. The rhythm of life was most amplified, in close connection with industrialization and productivity gains, on the modified technological background (speeds of production, of transport, of communication ...); overmultiplying management and control systems also helps to increase the complexity of life. 
From a structural point of view, the increasing number and extent of immaterial activities (services) must be observed. The service economy includes also, from a conceptual point of view, the increased spirit of serving in all economic activities (see the developments in sections no. 3,4 and 5 ).

The literature points out the idea of a new economy of quality (Karpik, 1989, quoted in Djellal and Gallouj, 2008), of an informational or computerized one, of a knowledge-based economy. Knowledge and such evolutions claim a complex issue of knowledge-based economy. It became clear that growth is the "daughter of knowledge" (Arrow, 1962, pp. 155-173); knowledge became an economic factor: besides the role of technological knowledge (about how to produce), the managerial, organizational element proves its contribution; the economic research has developed the theory of human capital and the intellectual economic factor (see the contributions of Theodore Schultz, George Stigler, Jacob Mincer and Gary Becker and (according to Jivan, 2016b, p. 25).

The intellectual factor (information, innovation, invention, knowledge, science, entrepreneurial spirit, imagination) is representing the stake in the service economy and in the knowledge society, in addition to the classical material factors (capital and labour, which are physical factors), and immaterial investments, generally speaking, became most important, as underlined by Jivan (2016b). In the respect of immaterial investments, please see the developments of Caspar and Afriat (1988). The essential characteristic of nowadays is the increased importance given to the intellect factor, in that what concerns its role in the economy and society, as resource and as well as result, as stake and as purpose.

Regardless the names and other characteristics, we highlight that the main aspect that defines the essence of the realities of nowadays world is the superior intelect-intensivity realized and proclaimed for the society of today and therefore for the economy. The complexity, immateriality and mainly the intelect-intensivity are defining also for the economy (Jivan, 2016b). Intellectual elevation and complex economic thinking should be found in the economy too, as well as they exist in the present human society. Such elevation and complexity (superior to the tendencies of simplicity) is the main "special quality" that justifies the claim of the economy to be actually renewed, if compared to that of the last centuries (Jivan, 2016b).

Here should be reminded the primary importance of the "intellectual services" 1 (education, scientific research, consulting and assistance services - including management, engineering economics, know-how, marketing; health services; cultural services etc. - according to Jivan, 1993, 2000, 2016b). In such conditions, the literature speaks about "rising returns" (Jivan, 2000), about generalized service or generalized spirit of serving (Jivan, 1993) or of service (dominant) logic (Vargo and Lusch, 2004; Grönroos, 2008); in this respect, please see infra the section no. 3.

\footnotetext{
1See Gadrey (1992, p 65 and others) too : he speaks about "fonctions intellectuelles" or "prestations intellectuelles". The sense is almost the same with "pure services": "services purs" is the terminology used by J. De Bandt in the special number of Revue d'Economie Industriele No 31/1985 (p. 186).
} 
The conceptual and topical frame of our debate is given today by the concept of knowledge society ${ }^{2}$. We do not develop here the issue of knowledge society, but we just invoke it in the purpose of claiming that it should better ground economic research from a conceptual point of view: the economy consistent with knowledge is an innovation one. In this context, economic research should not just innovate business approaches, but also develop reviewing and widening economics. The declared pillars of the new economy and society are human formation and professional training, research and innovation (in such respects, please see Jivan, 2016b, p. 27-32 and the references there in). The economic realities are more and more advanced from the technical and technological point of view.

In our opinion, it should be added that advances from the human and complex sighted points of view should at least equally be considered. Responsibility in the knowledge society and in the new economy, based on knowledge is thus another issue to be actually taken into account in theory and in practice; in the complex approach consistent with knowledge society, the ethical concerns may be reiterated too. They must not be anymore ignored because of the absolute priority given to economic interests. Short sighted and unilateral approach run counter knowledge society and knowledge based economy. The level of knowledge requested and allowed by nowadays society grounds the economic thought, on reviewed - and more rigorously chosen - elements of knowledge society.

Other dimensions of the new economy can be pointed out. The main concern of our paper comes firstly from and is linked to the issue of service. In the context of the dematerialisation and increasing complexity of the economic life, firstly of the transactions' objects but also of the nature of the „production”, in the last few decades the economic realities got rather atypical forms. In this respect, the contributions of the service economy in describing the unusual character of the market should be better taken into consideration. They were identified in the case of the increased (and increasing) immateriality of the economy and in the case of the bigger and bigger complexity of the offers of nowadays. More "immaterial" and more "experiences" are being offered and bought, rather than simple, tangible objects. The economy has more and more elements, characteristics and functionalities that do no longer fit the ones that stood at the basis of the orthodox thought and economic analysis.

Such evolutions are more spread, not only due to the expansion of services, but also with the expansion of the market that shows more than ever characteristics that are not always well captured in the common models. (The usual dominant models are designed for material goods, with quantities and evolutions strictly discrete.) In the context of the generalization of the character of service of the economic activity, the atypical character shown by the services' economy shows its generality, being actually more adequate than

2The literature highlights the passage from the information society, to the knowledge society (Daniel Bell, 1999; G. B Fisher, 1935; Jean Fourastié, 1963; V. R Fuchs, 1968; and many others, including Alvin Toffler's "waves", Toffler, 1983). The information society is about the explosion of the Internet; the knowledge society is defined as representing more than the information society; knowledge is obviously at the center of attention; the environment in society is intelligent. All vectors of knowledge are based on the character of the infinite public information (Drăgănescu, 1987 and Filip, Ed., 2001). 
the models that are suitable for the strictly material production (Jivan, 2000). See also infra section no. 3 .

These are the main reasons that justify the need of a new approach (firstly of value and of generating value). Our approach puts in question certain core elements of such debate, aiming at broadening the horizons of economic understanding.

Approaching economic research on better informed grounds means that, apart from extremely developing management and marketing techniques (that seems to be in the core of the economic research in the last decades), also the issues of value, value production and other such most common (theoretical) issues should be reviewed and more profoundly understood. Such putting under question is required because the way they are commonly approached allowed (and continue to allow or even to urge/incite) the destruction of the natural environment, the polarization (social problems) and the building of the private and present economic growth (productivity growth, profit growth, consumption growth ...) on the accounts of the general and future welfare (the next generations here included). Therefore, innovation and responsibility, that we previously noted, should be, in our opinion, mark elements for searching enriching and, as a result, improving the economic approaches and analyses.

Such more ample, diverse and more profoundly concerned issues must be found in the perception by the economic science. In addition to the strict economic realities, the complexity of world where such realities are included in should be in the core of scientific research; e.g. more many dimensions are to be considered (Jivan, 2015, 2016).

Under these circumstances, the problem of productivity should be concerned at the level of knowledge allowed/secured by the research in the field of service economy (see infra, also section no. 3); due to the non-typical nature of the nowadays economy (in respect to the orthodox theory), the usual productivity should be reconsidered. The most common use of the idea of value creation may be put under question (please see sections no. 2, 3 and 4).

Such qualitative and immaterial dimensions of the nowadays economy and society, and their increased complexity and possibilities as well, require an also renewed approach of productivity, suitable for the new realities [once aspects of novelty are revealed and seen in a new adequate light].

\section{Productivity - a problem from the point of view of measuring and against to the genuine liberalism}

Productivity, just as the term says, should be the specific feature of producing value, the quality of generating/creating value.

Knowledge (see supra section no. 1) should allow capital improuvements in this matter. In case it discovers inadvertences, truncating realities (capturing just parts of the reality) and distorting the senses that are favourable to humankind, knowledge claims/imposes such optimising; humankind should not persist in the "rush" for bigger and bigger 
consumed quantities (in the name of or for the purpose of registering productivity's growth), should not be preoccupied with the profits' and incomes' growth at any ("external") cost. Such growth is often artificially stimulated by market means, but ignoring the external effects and thus, is achieved on the account of the economic and vital resources of the planet.

According to Jivan (2008), Nicholas Georgescu-Roegen (1979) requires a widened approach concerning the entire world (its suffering natural environment here included) which could make better seen the growing entropy. He lets us know that each economic analysis is made under the cultural influence of an institutional model from the society the analyst better knows (usually where he lives in). Nicholas Georgescu-Roegen (1979, p. 521) speaks about the "specific institutional content" that fill the "standard" theory. The common industrial pattern of approaching the economic life, brought much production and productivity growth, but also in unwanted results (Georgescu-Roegen stresses the entropy problem, speaking, in an unusual approach, about the productivity in entropy).

As shown in Djellal and Galouj (2008), measurement errors bring economic policies and scenarios that are problematic (at page 26, the authors quote the Boskin Commission report, 1996, and also Eurostat, 2001 - idem, p. 27 etc.). They underline that "In a given socio-economic environment [...], the endogenous factors are linked to the characteristics of the indicators used and to the difficulty of compiling (reliable) data [...]. The numerous difficulties encountered in defining and measuring output, input and so on and the difficulties of aggregating data [...] give rise to measurement errors. [...] The doubts raised [...] relate to the methods and conventions used in the calculations [...]." and that "The exogenous factors [...] concern the fundamental changes affecting contemporary economies, which are causing chronic difficulties for the indicators used to measure productivity.[...] The indicators in use are rapidly being rendered obsolete by the dynamic of contemporary economies" (Djellal and Gallouj, 2008, p. 27). As the quoted authors say "exogenous factors [...] sometimes cast doubt on the conceptual validity of the notion of productivity" (idem, p. 28).

In the matter of economic indicators, we should refer also, for instance, to Hartmut Bossel's criticism of common indicators (according to Bossel, 1999), as well as to the analyses of indicators performed by Stiglitz, Sen, Fitoussi (2009). “[... A] statistic system that comes to complete measuring the market activity by measures that are centered on the human wellbeing and by measures that could capture the sustainability [...] must be plural without fail - as there is no singular measure that can summarize something as complex as the wellbeing of the members of society, our system of measuring must include a diversity of measurements" (Stiglitz, Sen, Fitoussi, 2009, p. 12; our translation. Thorstein Veblen criticized the abnormal consumption and waste, so common in developed societies (Veblen, 2009). With respect to the destruction of the natural resources of the planet, Jean Gadrey says: "the financial and ownership capitalism (still dominating) [...] threw us in a crisis that is even more durable as nothing important has been done in order to reduce the power of the annoying liberalised finance" (Gadrey, 2010, p. 18; our translations). In those last words of Gadery we find certain essential qualitative aspects that are missing from the race for growth. He also mentions that "The cult of growth is founded on forgetting the main society stakes: always more of what, for whom and with what consequences?" (idem). 
Such researches are pointing out the core problem that, most of the approaches (and indicators usually employed in economic analyses) show. The common indicator and the usual concern for productivity lose important parts of the analysed reality and, moreover, they can stimulate a wrong side of the incentives and can bring perverse effects, mainly in the long run.

Growing the indicators of productivity has an important contribution to growth for some economic entities, growth that on the other hand can have very destructive influence on the long and very long run. The fact that those that generate the "air or water polluting (the emissions of greenhouse gases is also included) do not pay the social costs of their deeds is a major distortion of the economy" (Stiglitz, 2013, p. 35). Such "efforts" or destructions - no matter who bears them (if according to the ones said above, we extend the horizon of perception of reality) -, are used in the calculus of productivity, of performance in general, of economic efficiency, as the denominator and are commonly considered as "external" (collateral effects) and therefore they are often ignored in the economic analyses (not only in the ones done by the economic units, but also in the general ones done by the economic science/economics). But they exist in reality and therefore, the scientific analysis that is consistent with the knowledge society and knowledge based economy should consider them (see the alternative approach offered by our paper in sections no. 4 and 5 ).

Djellal and Gallouj talk about "the (total or partial) conceptual invalidity of the notion of productivity" and about its abandonment (Djellal and Gallouj, 2008, p.28). They consider, for example that "the concept of productivity [...] loses its validity when applied to interorganizational comparisons and benchmarking exercises", implying the necessity of taking into account certain environmental variables and for multi-criteria evaluations (Djellal and Gallouj, 2008, p.29) ${ }^{3}$.

Such researches (their criticism towards indicators, formulas, ways of quantification etc.) give us the possibility to connect with the criticism of productivity (as normally computed) and with the necessity of an alternative (see sections no. 4 and 5, where we present the alternative of servicity and the opposition servicity-productivity).

In order to create the conditions for an accurate approach, certain old approaches on value and value production could be invoked. In Jivan (2016b) reference is made to Aristotle and his highlighting of the human (superior) activities, distinct against the inferior ones (those last ones being natural or hrematistics). The physiocratic approach on productivity - as generation of a net product, versus "sterility" - is also reminded in the quoted paper. The settings of such early economic liberalism deserve being reminded and put in correlation with the quasy-similar meaning that Adam Smith brought for productivity. But Smith also changed the productivity criterion, from the net product invoked by the Physiocracy to his commanded labour-value. The material production processes of the modern industry - during England's industrialization - were thus here included as "productive". And his approach became prevalent if compared with the impact of Quesnay's one. But he has also the merit of keeping the distinction between the value creation and the market effect, between genuine value and market price.

${ }^{3}$ The theoretic analysis done by these authors is very complex and well sistemathised. 
We do not devevelop here the debatable character of the quantitative and "energetic" criterion that the concept of value-labour involves. The classics adopted Ricardo's valuelabour (i.e. "incorporated" labour, labour imbodyed in the product) and Marx as well. The extending of such approach was made by Marx contribution, extention made in despite of the apart approach of $J$. B. Say concerning service connected to all production factors.

From the elder times, we remind here just the general approach on economic functionality of Frederic Bastiat (involving harmony in his economic approach), who conceived the concept of value-service as the core of the generalized market economy. His systemic economic vision must be underlined.

Other developments may be found in the qoted book, including the individualistic approach of marginalism (neo-classicism). In our opinion, the narrow or strictly specific approaches are responsible for insufficient taking into account of the so called "external effects", and thus for the economic approached that can be found nowadays in the irreversible - but stoppable - destruction of the planet (in respect to a widened economic approach, please see also see section no. 4).

In our opinion, a generalised Pareto optimality, on diverse dimensions (Jivan 2014) is thus requireble.

The marginal approach on the economy brought the mathematical development of research, with positive effects, but also with certain problems (see also section no 3). The distinct (during classicism) concept of price took, with the neoclassic thought, the place of value, ignoring the disctinctions made in trhe matter by the classic thought.

In respect to productivity, Djellal and Gallouj (2008) also present diverse aspects referring to definitions, methods of measurement, determinants, and strategies. From this volume, one can extract important details regarding the stages, determining factors etc. that can enrich a review of most important moments of scientific contribution to be mentioned.

Djellal and Gallouj (2008) offer a very well detailed, innovating and useful description, different forms and nuances corelated to the productivity indicator. They intended to analyse the common horizon of the enterprise (merchandise, financial, marque image, industrial-technique, therefore material and reputation on the market), taking into account also the social dimensions, the inter-humans relations, of innovation, focused on the interests of the company. Thus, the quoted authors develop the approach on productivity as a part of the concept of performance (that they consider having such a widen horizon).They use the concept of performance in the broadest sense in respect to productivity. But the area of focus (the conceptual content developed by the performance concept - privileged by these authors) can still be enlarged. Compared to the "performance" as defined and developed by the cited source, the servicity concept (Jivan, 1993, 2000 and others) is even more complex: the approach of servicity questions the difference between the approach (i) pro-individual advantage (gain) and that taking into account the (ii) general implications, no matter if they are physical ones, pecuniar ones, of added quality, effort, etc. (Jivan, 2014 and others; see also the developments in sections 4 and 5).

In the present paper we will not get into more details, the ones presented so far serving the purposes of the present work. The brief reminding concerning how value production was seen by the authors or the economic thought here evoked is ment to better ground productivity on the genuine liberalism. 
The genuine liberalism is privileged in our view as conceptual basis for the servicity concept that we'll further present in this paper (see mainly the developments in the next sections). After the physiocrat approach on value (purely materialistic) became obsolete, under the impact of Adam Smith's scientific personality and economic work, there are new approaches: Bastiat's approach of value, the Ricardo-Marxist value approach (labour incorporated in merchandise) and the marginal approach. This latest one became (and still is) dominant. Still, it is subject to a trap that the economic science can fall into: namely that the method (tools used) dictates the theory (concept, understanding) and influences it, alters it and disorients it, presenting as the truth something that the method (tool used by the theory) is capable to do and show.

In other words, the limits of mathematics to express the complex social phenomenon of the economy lead not only to excluding from the analyses and research everything that the marginal calculus cannot express, but almost to consider that they do not exist or are not relevant to be considered, at least from a theoretic-conceptual point of view. So, for example ${ }^{4}$, the economic research ceased to consider the idea of value, idea which was given up once marginalism was imposed, value being often confused with the market price. For such reasons, and on the basis of genuine liberalism, we consider this last approach (that became central in the economic thought and research, but mainly due to methodologic reasons) as peripherical (from the point of view of scientific reasons) to the fundamental economic concepts (we take into account, in expressing this opinion, the more profound and larger validity approach of the classics).

Regarding the three previously reminded approaches on value - Ricardo's and Marxian value-labour, Bastiat's value-service and the Neoclassical value-market price -, the economic science developed the first and last ones and the last one gained the unanimous usage as it is the most prolific one. Maybe it became dominant also due to its more mathematic character; it is more fit to mathematical developments that are so much liked and useful to the economists. This preference leads to important developments in the economics and business research. Still, we consider that from the point of view of the conceptual depth that stands at its core, the fundamental one - that includes best the genuine liberalism spirit - is Bastiat's approach: the essence/the spirit of the generalised market economy. "If we really accept exchange as being the centre of economic life (and not the production), and if we approach the economic activity by starting from its functionality, then we can see that all human activities are made to be supplied to our fellows. In a market economy the necessities are covered through the indirect way of exchange, of inter-correlation between members of the society" (Jivan, 1993). The form described by Bastiat is the most complex and remains central in respect to the economic liberalism principles. It does not over emphasizes the material labour (as combination of matter-energy, as in Ricardo-Marx's approach), nor the methodologic-mathematic side (as in the neoclassic approach) that increases the risk of subordinating the theoretic thought, and the analyses, to the immediate application possibilities.

\footnotetext{
${ }^{4}$ Examples can be given to express the way economic research was robed, from the theoretic, ideatic and conceptual points of view, while it was inriched from the methodological point of view. The mostly published economic literature of today shows the interest (sometimes central) regarding the operationalisation and intense use of mathematics in economic research, sometimes by giving mathematics the role of waranty for the scientific character of the economic research, often with the price of loosing the conceptual depth.
} 
The service approach was the least valued one, despite the conceptual reserves it has (reserves given by the essences that fundament it from the point of view of reflecting the economic reality and further development possibilities). We consider this as necessary for a positive change of paradigm. "[...] human activities [...] have at least one economic dimension: that of the required consumption - the only dimension taken into account usually. The other dimension is less regarded upon: it is about the social functionality about the performed service (during a certain period of time or considering a paid price). We must consider the beneficiary's point of view, and that of the society as a whole, and not only the point of view of the supply. The productivity is the main characteristic that is searched for in the preparatory part of the economic activity. We should think that servicity would represent all the complexity of the service valences." (Jivan, 1993)

In such view, the usual manner of calculating the indicator of productivity should be put under question. Commonly the revenues registered are taken into account in a particular (specific) manner, and the "external" effects are often ignored and, therefore, the general effects are trunchiated.

Certain pioneer contributions concerning the idea of the generalised service (Jivan 1993) should be reminded (see infra next section). Such idea is consistent with the switch from the traditional strictly material perception on the economy, i.e. from the material production point of view, to a widened approach, putting the immateriality of nowadays economy and society in the place it deserved (see also sections 4 and 5).

The conclusion reached by the main literature that grounds the generalised service concept) consisting in the core meaning of the generalised service as capturing value creation in the knowledge based economy: all economic activities can be schematized in a general scheme (as designed in Jivan, 1993; see the next section).

\section{A necessary paradigm change. The generalized service}

Our paper starts from the idea that the common productivity, as it is usually calculated, has its part of responsibility in that what concerns the natural-environmental problems accumulated or the social problems still remaining; we consider that it is not anymore enough consistent with the higher scientific levels allowed and required by knowledge society. We are confident that better approaches can be found, and more pertinent models and analyses can be developed. Resorting to the reiteration of certain elements from the genuine liberalism (see supra section no. 2), and learning on the grounds of teachings from service economy (see infra, in this section), a pertinent way of approaching the defining trait of producing value can be promoted (see developments in the sections no. 4 and 5)

The growing number of services in the last half of century, their growing technical level and the high share that certain services have in most of the economies, can cause unpredictable consequences, practically modifying the whole of society (not just the economy), as was the case with the effects of telecommunications, electronics, information revolution. From the point of view of economics, the very visible development of services and the extension of the service principle throughout the economy generated the use, for today's economy, of a number of concepts like post-industrial, or non-material, 
or service economy. (It should be noticed that management, telecommunications, computer software are all services, them too.) The services sector has higher economic weights today than ever and is growing worldwide. And in tertiary activities, an increasingly important place is occupied by intellectual services. These realities cannot remain without effects in the general economics (see infra certain concrete developments).

Therefore we will here remind contributions, certain of them may be well known, others less known.

Mihail Manoilescu brought an enlarged horizon in assessing the economic activities in the 30s of last century. Taking a systemic point of view, he took into account a superior level in respect to the economic entity: e.g. he is interested in the productive character of the economic activity, especially in the case of less developed economies (those insufficiently industrialised) and he is preoccupied by the level of the national economy in the international systemic assembly. He underlines that a company, even if it is very profitable, can be less than sufficiently profitable for the nation (Manoilescu, 1986, p. 98 and the next ones. He highlights the differences between economic sectors, from the point of view of productivity, but not according to the criteria of materiality but according to that of technicity, involved capital (for example, he emphasizes the reduced productivity of the agricultural countries in respect to that of industrial countries).

Against the most common approaches in economics, when speaking about productivity, Nicholas Georgescu-Roegen also adopts a widened heterodox view, stressing the issues of "productivity in garbage" and "productivity in entropy" (Georgescu-Roegen, 1979, p. 521).

In 1957, M.J. Farell delimitated (in the economic ${ }^{5}$ efficiency) the existence of technical (or productive) efficiency and allocative efficiency. The first one speaks about quantities (the quantity of output in respect to the quantity of inputs); the second one speaks about values on the market, taking into account the prices gained by the concerned economic entity, for its output, and the prices paid for its inputs.

An important literature was developed concerning the topic of services and service economy. We may quote for their contribution to service economics, for instance, Fourastie (1949), Lengellé (1966) V. Fuchs (1969), M. Olson (1972) and other important authors. Most important for our paper is that certain of them developed also the topic of productivity in services itself, stressing on the implications of immateriality. It is also necessary to understand the role of immaterial investments (Caspar and Afriat, 1988); and the principle of investing is most important for reviewing the meanings of economic activities, hence the long-term and very long-term effects (Jivan, 2011) overcoming the

5Called economic efficiency by Djellal and Gallouj (2008); in Farell's terminology, it is called "overall efficiency" (according to Djellal and Gallouj, 2008, p. 14). 
immediate (Gadrey, 1992) and short-term approach. The connection with reviewing the conceptions in the productivity field is here included. They contributed to grounding possible important generalizing approaches (Jivan, 1993) and thus, other scientific advances (see infra, in this section, and also the sections no. 4 and 5; we exemplify mainly Gadrey, 1996, De Bandt, 1991, Gadrey and De Bandt, 1994).

Other contributions in the general service approach/generalised service can be exemplified. For instance, referring to Theodore Levitt and his research concerning business growth (Levitt, 1974), Christian Grönroos comments that his vision "means that people do not buy goods and services for basically different purposes" (Grönroos, 2008, p. 301). From Levit we should keep in mind that all services are created with resources and service creation means creating value (therefore, Bastiat's theory is, from this point of view, at the core of this author's beliefs).

Immediately after Levitt we should mention P. Hill (1977) who brought at least two important clarifications from the conceptual point of view: he made the now well known distinction between service as a process (servire in Romanian) and service as outcome (serviciu in Romanian) ${ }^{6}$ and "an analytical dissociation between the customer and the medium of service provision". Therefore, he "first formulated such a general definition of services". (The cited texts are from Djellal and Gallouj, 2008, p. 39, where in Hill is quoted and where from we took those information).

We do not intend to make an inventory of al contributions to service economy. In our paper, we just mention a few papers that we consider that opened new special directions and influenced the scientific research in the field, in respect to our topic, namely to its application in respect to productivity and with a certain emphasis on the generalised service.

In 2008, citing one of his articles from 1979 (written in Swedish), Grönroos says at page 301: "The citations from 1979 [...] imply that goods and services are consumed in essentially the same type of process". Still, we have to notice that the scientific idea followed by Grönroos is different from the one we are interested in the present paper: namely, he is preoccupied by the value as consumption issue (for this he uses also other sources than the ones we present here from Grönroos, 2008); we are interested in the principle of serving in the economy (as generally valid principle for the market economy, regardless of the material or immaterial aspect of the economic activity).

\footnotetext{
${ }^{6}$ Such problem - that generated a big number of research pages in the literature in English and in French, for instance (where there is the unique term or name of service) - does not exist at all in Romanian, where there are two different words, one for the action (i.e. the long infinitive of the verb to serve), on the one hand, and another for the result of the action, on the other hand.
} 
Jacques De Bandt (1991) speaks about "pure services" (the most immaterial activities of the economy) and about characteristics connected to the services' productivity.

Also important are the researches of Jean Gadrey (1992 and 1996, for instance). Starting from the definition gave to services by Hill (1997), he extended and clarified it, providing the scheme of the 'service triangle', as shown also in Djellal and Gallouj (2008, p. 39 and next).

The ideas expressed in Jivan (1993) follow the literature review regarding the service economy that was already well developed and still ebullient at that time ${ }^{7}$. The cited paper brings a qualitative improvement: the generalised approach, approach that regards the whole economy and the economic science in general. This approach can be found in the servicity theory (that is described in respect to a few essential aspects in the quoted paper $^{8}$ ) and starts from the general scheme of an economic activity, which is later called the scheme of the generalized service (Jivan, 1996).

It designs an economic entity (client) which orders to another economy entity (performer) a certain service. In the purpose of accomplishing the economic command, the economic agent (who carries out) has to conceive, to prepare and organize the suitable activity, also obtaining materials, information and other resources. After such immaterial and material preparations, the proper work (performance) may proceed (consisting in diverse manipulations of resources, modifying them, even manufacturing objects etc.). When all is ready, from the point of view of the performer, delivering and, thus, accomplishing the command may be done.

This "generalised scheme" of the generalised service starts from the same conceptual logic as the Gadrey's service triangle (Gadrey, J., 2003, p. 19) ${ }^{9}$, as these logic representations

\footnotetext{
${ }^{7}$ Services World Forum was also active in the scientific field (as an independent association, supported by its membership contributions), and aimed to facilitate and stimulate an open dialogue and professional interest on that what concerns the role of services in the economy. It aimed at increasing attention on the issue, among economists, business leaders and policy-makers. Its members were involved in research and education. Information on researches, articles and papers on the field of services were also published (including an internal Bulletin/Newsletter). It was organising conferences and meetings in this respect.

${ }^{8}$ Later developed in many articles and books, such as for example Jivan (2000) and (2014); see also other references in the present paper. The economic conceptuality connected to the presented topic started to emerge a few years before. Among the published papers from the 1985 - 1993 period, we mention just Al. Jivan (1985), "Objectives Qualitatively New in the Small Industry Activity", Revista economică, no. 50, p. 13; Al. Jivan (1988), "Efficiency in the Context of the Economic Growth Becoming More Intensive", Revista economică, nr.45, pp. 19, 22; Al. Jivan (1993), "Considerations About the Productivity of Intellectual Services" in the volume Transition Towards the Market Economy in Romania, University of Timişoara, p. 350, all published in Romanian.

${ }^{9}$ The schemes of Gadrey are quoted also in Jivan (2016b), namely, apart from the services' triangle - that is reproduced as such -, the hospital services pentagon (from Gadrey, 2003 p. 18) is generalised under the form of the Pentagon of intellect-intensive services (Jivan, 2016b, p. 180).
} 
expresses the same reality of service. The approach in Jivan (1993) adds from the conceptual point of view the generalising to all economic activities of the market economy (having therefore a higher degree of validity): it is generally valid, i.e. for immaterial performing and as well for material productions), highlighting the character of service they all have (that not only those with a higher degree of immateriality).

It is important to be pointed out that most of such researches in the field of the service economy have as conceptual core, the service-value introduced by Bastiat.

Essentially, the genuine idea of the generalized service comes from Frederic Bastiat, for whom any economic activity is a service, a man performing for creating satisfaction to another (see our quotations in section no 2). For Bastiat, everything is defined not by material goods, but by the services offered: any social activity is a service, because it represents an effort to a man for satisfaction to another; the exchange itself is accomplished through serving processes. The form of the generalized market economy is the generalized service (Jivan, 2016b; see also the generalized service concept, in Jivan, 1993). If we take into account that Bastiat put service in the core of value in the classicism period, the theory is no longer a novelty; but considering Bastiat as a simple extoller of the liberalism in the economy, may empty his image of its main role in the economic science. His main contribution is exactly putting the service in the centre of economy, the defining character of service for value itself. But this idea became actual again just towards the end of the $20^{\text {th }}$ century.

Ritelli, Barbiroli, and Fabbri (1997) refer to "satisfying the needs of businesses on the one hand, and society as a whole on the other". This specification is important for the concept of servicity (see sections no 4 and 5), therefore we mention it here, even though the cited authors are preoccupied in their research by completely different aspects than those that we analyse in this paper ${ }^{10}$.

The service literature provided interesting developments dealing with the scope we are concerning in the present paper, focusing on value creation in terms of service or "services utilities" (positives or negatives, i.e. externalities here included); such terms being applied to services and to material goods as well; see particularly, for instance, topics like: "circular economy", "functional economics", "economics of experience", the representation of product and innovation in terms of characteristics, co-production (with the customer); such contributions are referred in the introduction of the paper of Jivan

\footnotetext{
${ }^{10}$ For example, regarding the approach at society level as a whole, the main concerns of the cited authors refer to the problem of regulations regarding "the rules according to which business must operate", in order to ensure the free competition. The servicity approach opposes the two categories of interests previously mentioned, in the sense that satisfying the needs of businesses doesn't obligatory lead to the optimum at the level of the society as a whole. Mihail Manoilescu had underlined this in the 30s of last century (see above in this section). We consider that it is justified to check the correlation of the two (at individual and systemic level).
} 
(2014), quoting their authors, like, respectively, Stahel (1997), Pine and Gilmore (1999), Gallouj and Weinstein (1997), Djellal and Gallouj (2008); In that what concerns the issue of co-production, references may be made, for instance, to Jivan, 2016 a.

From such developments we remind mainly the core idea of defining the product by its service characteristics, even if it is pure service, or material good: this means that the role or function accomplished is more important than the form - be it more or less material or immaterial.

Regarding the unitary character of the material and immaterial economic fields from the point of view of their role as service, mentioned above (Jivan, 1993), Pim den Hertog (in Gadrey and Gallouj, 2002, Edited by, at page 225) says: "a continuum rather than a strict distinction between manufacturing firms and service firms [...] seems appropriate when discussing firm innovation. The heuristic model to be introduced [...] can be used for discussing service innovation in both manufacturing and service firms." Other sources can be considered and discussed according to the approach of the present paper.

In the same matter of the generalised service (Jivan, 1993), we also have to mention that Vargo and Lusch (2004) and Vargo and Lusch (2008) - and also other important developments by those authors - have a special merit in imposing in the economic literature the service dominant logic (SDL).

An important source of information concerning the value production is given by Marco Galvagno and Daniele Dalli (2014), in their "Theory of value co-creation: a systematic literature review". Also, in the cited paper, there is a relevant definition of the service science: "we define service science as an emerging interdisciplinary field of inquiry that focuses on fundamental science, models, theories, and applications to drive service innovation, competition, and wellbeing through co-creation of value." This definition belongs to Ostrom et. al. (2010, p.5) and is referred in Galvano and Dalli (2014), where the relation with service dominant logic is also highlighted.

A certain number of essential elements of the service theory must be recognised as valid for the whole economy, not only for the strictly immaterial economy (the material production is also part of the market economy, of the economic life, as activities meant to serve certain clients). "We shouldn't face the services as a kind of production (a different one but anyway a production) but to face the industry as a kind of service. Thus, any kind of production should be regarded as a preparation of the final delivery to the client (for and towards the client)" (Jivan, 1993). We underline that the material production is just a particular case of the generalised service and not vice versa: the "immaterial activities" are not simply a specific case, which emerge after the industrial and agricultural production. It is true that the phenomena of services became visible for the economic science only after it was developed on the basis of industrialisation (namely the 
industrialisation of England). And, as we already said, services have always existed. Bastiat spoke about the value-service in the classicism time.

In the matter of economic indicators, please see our references made in the section no. 2.

As it was shown as a problem in that what concerns the value production (see section no. 2), productivity proves itself to be a problem also from the point of view of service economy. Important information can be accumulated from the service economy. In respect to designing the productivity indicator (the way it is computed - that had an important influence over the way productivity is perceived), the usual neoclassical approach is taken commonly into account. It means employing the quantity of the good that is "produced" by the concerned entity (or "consumed") and its variation at the limit. Such approach is suitable for perfectly divisible goods (material goods). But here comes one main dominant feature of service processes: due to immateriality, services do not allow measurement (and division or counting) in physical units. So, in principle, such approaches as discrete quantities do not apply to services. This is the case of two thirds in the nowadays economy (at least, the case of the most advanced economies, which represent the weight of the world economy).

Moreover, it should be noted that all activities get such feature, thanks to the growing service spirit of all economic actions. The supplies are growing in complexity and the economy is developing in such spirit of generalized service (see Jivan, 1993 and, infra, the more recent developments on the idea of service logic). If we take into account those developments, we may say that even the material productions (that became much more advanced and complex from the technical and scientific point of view) could be included in such a non-discrete approach. Under these conditions, the marginalism that has dominated economic science for almost a century and a half (since 1871) may be put under question, at least for most of the economic activities (only a minor part of the economy still have conditions actually suitable for the neo-classical approach concerning discrete quantities). Such approach remains justifiable only if all data are analysed as values, i.e. by employing market prices.

The literature concerning the phenomenon of services described and analysed (mainly beginning with the last decade of the previous century), the specificities of services and their consequences for the definition of productivity (Djellal and Gallouj, 2008, make a synthesis of such researches, in their most relevant aspects; see, for instance, p. 33 and next).

in our opinion, it should be seen that such developments of the economic literature do not concern only the services, but the whole economy and, therefore, the general economics should review most of their approaches (which were made in the material industrial optics) and should adopt the widened view opened and allowed by services economics and required in the conditions of knowledge society. The most important reason for such 
switch from the materialist approach to a more comprehensive one (which we've also already mentioned) is given by the growing immateriality and complexity (especially from the technical point of view) of the whole economy and by the service element: this mark is characterizing the entire market economy, and not just the services (i.e. both material and immaterial industries). The characteristics of the market of services (Jivan, 2000) are in nowadays, already defining the new market development. Given the service economy, with the high share of services (immaterial activities) and, mainly, with the generalized service approach in all economic activities (even in the immaterial ones), the characteristics revealed by service economy became suitable for the nowadays' economy as a whole.

The contributions start from the immaterial character of most of services, pointing out the problems concerning the impossibility of "producing in advance" in the purpose of offering services later, describing the "perishable" character, the concomitance of serving and benefitting (they are not distinct processes, as they can be in the case of accentuated materiality - as "production" and "consume"); the important place of the subjective dimensions and of the psychic and emotional elements were also pointed out, the strong human relational component, with the client having its own role in performing the service, the diversity of such service activities and the unique character of actually each performance distinctly and so one. The aspects revealed by such new aspects that have to be taken into account - apart from the commonly concerned characteristics of "production" (by the old case of material production) - include the non-discreet character too, i.e. not suitable, from the scientific and conceptual point of view, for the usual marginal calculus.

Unfortunately, such contributions are not used enough by the economic science, in the sense of understanding value creation and the "productive" character through the service approach, by the criterion of service; mainstream economics remains mostly on the basis set during the industrialization of England (basis that are specific for the industrial material production) and the contributions of service economics are kept as side contributions from the point of view of general economics. This theory has its place more in business (mainly for marketing). It is seen more as a "logic" in which the economic events can be presented, if this service logic (Grönroos, 2008) becomes or is accepted as main or dominant (see the service dominant logic, Vargo and Lusch, 2004). In Jivan (1993) it is considered as generally valid, therefore as being unique in the economic activity (not only dominant in the marketing approaches). Despite the fact that SDL is well known/famous, we consider that the concern for service and the propensity to service should be taken into account in economics rather as a spirit, as a manner of understanding and approaching the economic activity, than a logic of marketing. From the general economics point of view, we consider that restricting the use of this idea only to the field of marketing, this reduces the concept of service exactly to the "market value". Or, in the light of the distinction made by the genuine liberalism (see the previous section- 2), one 
should take into account that this fundamental, general, abstract value should not be confused with the immediate, subjective, market one, with the price). ${ }^{11}$ And what cannot be included in the empirical calculus was rather left out of the theoretical reasonable assessing.

For economics, it is a capital distinction, introduced by the Physiocrats, supported and discussed by Smith and other classics and that was ignored after we've past to the marginal calculus: the advantages of introducing mathematics in economy came with the cost of ignoring this fundamental conceptual aspect because value is not instantly measurable.

More than this, the idea, is diverted in certain marketing developments on a particular direction, namely that of the customer service logic.

Thus, we consider as appropriate a change of perception, aiming to enlarge the perception of the economic realities, in the conditions of the last decades. Such an enlargement is possible due to the scientific developments brought by the service economy; because it is the economic science of services that facilitated and even generated such an approach It is necessary that such an enlargement is well understood by the general economic science (at its largest sense).

\section{Servicity as innerand generalised productivity of the economic entity or action}

Different approaches of value can generate different conceptions on the creation of value added and therefore on productivity itself. As a result, after our short references concerning the knowledge society (section no. 1) and mainly the issue of productivity as seen in the genuine liberalism (section no. 2) and as could be criticised from the point of view of the usually calculated indicators (section no. 3), in this section, we also refer to the issue of productivity as put in the context of the development of service economy.

When we said previouslythat the knowledge development may request the review of calculating productivity, we had in mind the fact that the challenge of productivity through competitiveness and the concern for growth in consumer society has distorted the genuine concepts, replacing the focus on value creation, by the focus on appropriation of values (Jivan, 2014): productivity is commonly calculated as the incomes volume (revenues) obtained by a certain economic entity with the factors employed.

Based on the nuances revealed in section no. 2 and on previous researches cited there, we can underline that the private productivity of an economic entity, as it is computed,

${ }^{11}$ Even if, with the marginal approach generalisation in the economic thought, such a distinction is no longer discussed. 
captures the way in which certain specific, punctual, private purposes of the economic entity (competing with other economic entities) are reached. Thus, the stress is on getting the biggest revenues from the environment of the concerned entity, by market skills. The other effects that an economic activity can generate (i.e. concerning the environment itself) are usually let on a second (less important) plan. As a result, the capitalization of the opportunities and of the environment is often accompanied by problems affectingthe natural and social environment.

The focus on market private competitiveness often risks (already visibly) to become antisocial and anti-ecologic. Or the economic science must analyse such general effects too, not just the specific (private, local, or momentary) one.

The approach we maintain in the present paper is not from the perspective of the incomes, but from the perspective of the rendered service (service rendu). We want a straight immediate understanding: we do not consider the perception by the indirect effects ("filtered by/through the market"), as remuneration of certain economic activities; but we consider directly the actions performed by the analysed economic entity themselves; this is because ( $i$ ) the cashing the economic entity attracts can be influenced or generated also by other factors than the provided service itself, performed by the entity toward its exterior (the beneficiary, the environment in general); for example, the income can be increased or decreased through special market abilities, by modifying the connections and force differences that exist between diverse business partners, by various contexts, by subjective aspects and because of other conditions and determinants that are not part of the benefic contribution brought by the studied economic entity (the rendered service); also, we could take into account (ii) other effects too, other aspects of the contributions of economic activities, including those commonly considered externalities, in a more complex vision.

Therefore, at the opposite pole regarding the common approach of productivity, we can consider (from the theoretical point of view) the concept of servicity, as aiming generally valid targets, beneficial to all, in the generalised Pareto sense (Jivan, 2014).

The term servicity was conceived as alternative to the term productivity ${ }^{12}$. The idea of servicity introduced by Jivan (1993) was further developed in later papers (here we just

\footnotetext{
${ }^{12}$ By developing the principle according to which P. Eiglier and E. Langeard (1988) have introduced the term servuction, as alternative (for services) to production. Their idea was useful as "servuction" was going to decribe the action of serving, in the context in which in English and French (as showed in a footnote of section 3) there are no separate terms for the action of serving and the result of serving, but just service for both. The concept of servicity means more than "productivity afferent to services" as alternative to the common productivity, actually suitable just for material production. This is a majour conceptual difference in respect to the approach that was at the basis of Eiglier și Langeard's proposal. Namely, servicity concernes both material and immaterial activities, taking into account a larger conceptual horizon, that doesn't follow the criteria of the materiality of the economic activity; it is fundamented exactely on the generalised concept of service (Jivan, 1993).
} 
exemplify Jivan, 2000 and 2014). Servicity expresses the horizon afferent to the quality trait of creating value (the sense from the initial liberalism associated to the production idea). In the optics of value-service (Bastiat), such specific featurecaptures the meaning of the generalized service (see the developments in section no. 3), of performing activities in the economy of the last decades, i.e. of rendering service.

Thus, servicity is the inner (actual) specific quality of creating value (new production) by the analysed entity or activity and it involves also the effort of generalizing the criteria concerned when improving the concept of productivity. There results an opposition: genuine productivity vs. actually calculated productivity, as shown in the synthetic table in section no. 5 .

The ideas developed in Jivan (2014) can contribute to establishing and supporting an approach, from a different angle than the usual one, for the productivity; the approach of servicity is based on the conception that all economic market activities are addressed to other members of the human society: "The functions fulfilled by each economic agent in the economic and social mechanism exist under the form of services that are done to the beneficiaries, to the business partners and to the society as a whole." (Jivan, 1993); the orientation towards the beneficiary became an important mile stone in the economic theory, by extending the theory of service (see supra, section no. 3). The economic life uses from a long time the generalised service; thus, as shown in the previous section, the economic theory just must accept it in the representations concerning this economic reality. Therefore, in the approach we've adopted for this research, the fundamental dimension of all economic activities is the service provided to the consumer or individual user $(a)$, or to other economic entities, but also, in a larger meaning, to the economy or society in general $(b)$. We consider that the approach of value-service (Bastiat, 2011) is definitory for the present economy that is a service economy (see section 3). Here, we just want to underline that, in our conception, the orientation towards the client shouldn't be regarded just as a manner by which the economic entity increases its market competitivity (its productivity, its profits), but every economic activities should be specifically analysed from the angle of its results for other economic entities or for the environment in general too. The private-individualistic analysis is done by any enterprising entity; in that what concernes the economics analysis, it is better to estimate the rendered service (the service performed by the enterprise) seen directly from the point of view of the beneficiary (and of the environment of the enterprise) and estimated in real forms, even though the approach and the real forms of estimation are out of the common computation manner.

Servicity in a narrow sense can be realysed in an optic that is rather opposite to the productivity, or at least corrective in respect to the productivity, i.e. on the line of value valid for the clients of the analysed economic entity. According to Jivan (2000), servicity in a narrow sense can focus on analyses concerning the clients or suppliers of the analysed economic entity or on other economic entities that have economic connections with the 
analysed one. As we have already mentioned, the nature should be considered too, in a specific, distinct way: the natural environment can be affected by that activity (usually through pollution, but one shouldn't exclude the possibility of positive externalities).

The most comprehensive version of servicity in narrow sense is the one that tries to include in the calculations the entire "external" social and planetary context (that surrounds the economic entity that is analysed). In such researches, there are limits: the data bases are created according to the logic of productivity and economic growth. The limitations depend on the level of knowledge and on the human capacity of imagining perceptions out of the dominant orthodox economic thought frames and patterns, on the incapacity to imagine or measure the effects in time (Jivan, 2011).

Servicitaty in a broad sense (Jivan, 2000) includes all the benefits generated, for the concerned entity and for its environment (i.e. "external") as well, on the line of generally valid value (not specific, punctual, not exclusively private). In order to get the larger sense of servicity, starting from the case of the narrow sense, we just have to add to the numerator the gains and to the denominator the expenses of the economic agent, in order to also include the productivity got for the economic agent, in the larger notion of servicity. From the point of view of the methodology, for summing up, one can use the uniformized values of the terms (otherwise heterogenous).

According to this heterodox approach, the sense in which certain usual indicators are used can be revised. As examples, the physical production, the value production, the number of jobs created. For example, for expressing in the optics of servicity the rendered service one could use directly the production in physical terms (real output) - that is found as direct effect in the environment of the analysed economic entity - and the number of employees. This number is found as a positive effect for the entities upstream of the analised ones (namely for the suppliers of labour services). Therefore, one can design certain ratios or indicators, using the same methodological principle as for the calculus of productivity (a ratio of the same kind as the indicator of productivity, but applying a renewed logic, in a different optic: approaching servicity accorded to the rendered service criteria). In choosing the indicators used for the empirical analysis and in the effective manner of including them in the analytic calculus, the concept of servicity should be found for the general benefit, according to the Pareto's optimum. Other aspects of creating the servicity indicators reside in the elements presented in the comparative table from section no.5.

We underline that by giving up the usual optics regarding the productivity computed for the immediate interest of the economic agent, preferring the optics of the rended service, new aspects can be revealed beside the most used ones, aspects that can be more interesting from the global point of view than the ones describing rentability or market competitivity; for example, this way can be revealed the social or ecologic impact (therefore other forms of efficiency and efficacity, such as their serviceability). 
As shown in section no. 2, the genuine concept of producing means creating new net value, as most general elements; it has not a peculiar meaning (neither an individual or local one, nor it concerns just a specific time); the production of value is approached in the most widened way. ${ }^{13}$ In the optics of servicity, the environment is considered as a co-producer, next to the analysed entrepreneur. Therefore, it should be present at sharing the results, the "production"; in the context of the knowledge society, the emphasis is on the creative and scientific factor, as principal factor, in respect to the importance of the contribution (Jivan, 1995). The cultural component (the locally dominating culture) is here also included: such culture gives the general value benchmark, here being taken into account the social and environmental responsibility as well, the respect for the nature and for the other entities.

Sedlacek (2012) is concerned with the "good and bad" in the economy and says that "good" and "bad" exist, even if the mainstream economic thought tried to get out of the discussion such aspects as being "value judgements" and outside the area of the economic science. We consider as un-scientific to analyse the phenomena of human society (the economy here included) by ignoring parts of the reality; namely, the economy is just a part of the human society life, and the value judgements can lack only with the price of some cuts that involve assuming too simplyfied approaches.

With respect to the systemic complexity of nowadays realities, the diverse connectivity and inter-relationality must be taken into account in scientific analyses (please see the short reference we made in section no. 1 to relational economics and to Barabasi's theory of connectivity). See also Jivan, A. (2016a), as well as Jivan, 2013b. "The productivity of an economic entity is usually calculated as a ratio: the nominator is the quantity of output multiplied by the selling price; the denominator is the quantity of factor (input) multiplied with its buying price.[...] the servicity [...]could be estimated also as a ratio, but in opposition with the calculated productivity: the nominator(1) can be the quantity of output multiplied by the lowest selling price on the market; and the denominator (2) can be the quantity of factor (input) multiplied with the biggest possible buying price resulted from the market negotiation." (Jivan, 2016a). By renouncing to the difference from such lowest selling prices to the possible (actually negotiated) one, the first calculation (1) lets out the values that are appropriated by the economic entity from its customers (ignoring the transfers from those); by renouncing to the difference between the possible (actually negotiated) buying prices and the biggest one on the market, the second calculation (2) lets out the values appropriated by the concerned economic entity from its suppliers (ignoring the transfers from those last ones too).

\footnotetext{
${ }^{13}$ In Jivan (2014) main directions of the widening of productivity approaching horizon are presented. Seeinfra the developments in the comparative table, next section no 5.
} 
The differences of calculated productivity come, to a great extent, from the mechanisms of the free market, including globalisation. The big influence of certain domination forms makes it impossible for the scientific research to ignore them. Factors (different from the intrinsic value) influence in an on-equitable manner the results registered by certain entities. The manner to register productivity (as it results from the market mechanisms) is differentiated also according to the national criteria (Jivan, 2014). We consider that any analysis of this should start with Mihail Manoilescu (who tried to bring corrections to the dominant economic thought, in the context when the differences of conditions between economic entities from the world's market shouldn't be ignored.

In the paper of Phillipe Cazenave, Christian Morrison, "Fonctions d'utilité interdépendantes et théorie de la redistribution en économie de l'échange", Revue Economique, March 1972. - cited by Fr. Perroux (1974), they talk about the "intellectual change of scene" in opposition with the type of analysis "obsessed by the pure exchange". This kind of analysis gets out of the ordinary "economic universe made up of agents [...] submitted to the neutral arbitrage of the competition price. It reintroduces the inequality between agents and the diversity of their motivations. It gives back to the economy the power in the form of influence [...] and [...] the forced transfer" (Perroux, 1974, p. 86). We add the comment that the inequality that Perroux refers to in the above quote is of course a different one than the difference from the individual quality point of view. The quality traits or specific intrinsic features are the only ones considered by the traditional model. This model of the market economy ignores the inequalities of power, size, influence, pressure acts or inequalities in the market negotiation. Such simplified model does not fully represent the reality. The possibility of certain "value transfers" occasioned by the market relations is considered also in Jivan, 2013a, 2015 and 2016a.

According to the above-mentioned aspects, we can observe that the optic of servicity gives us an unusual perception, even opposite to the common one, in respect to the indicators that are usually considered.

\section{Comparative table: servicity vs. productivity}

The role of service, the function actually accomplished by the concerned economic entity or activity is the actual economic efficiency of such economic activities and of all economic entities. The ideas, findings and proposals concerning our topic are comparatively presented in the defining table no. 1 that designs the main differences that, in our opinion, describe the servicity as opposed to productivity.

This table is an instrument for developing in a comparative way the main ideas of the concept of servicity, against the usually calculated productivity. It starts by presenting the frame of the approach (the conceptual frame of the matter). It sets clearly the horizon of the concept of servicity, which offers the main differences if compared with productivity; after, we highlight the approach manner (from the exterior, and more, as service offered 
by the environment and not as " production » created by the economic entity itself), for better understanding the details to follow. On the already set foundation (after describing a few aspects), we can, towards the end, describe certain implications, give a definition and we can better talk about the indicators that can describe the concepts, showing the practical importance of this approach. 


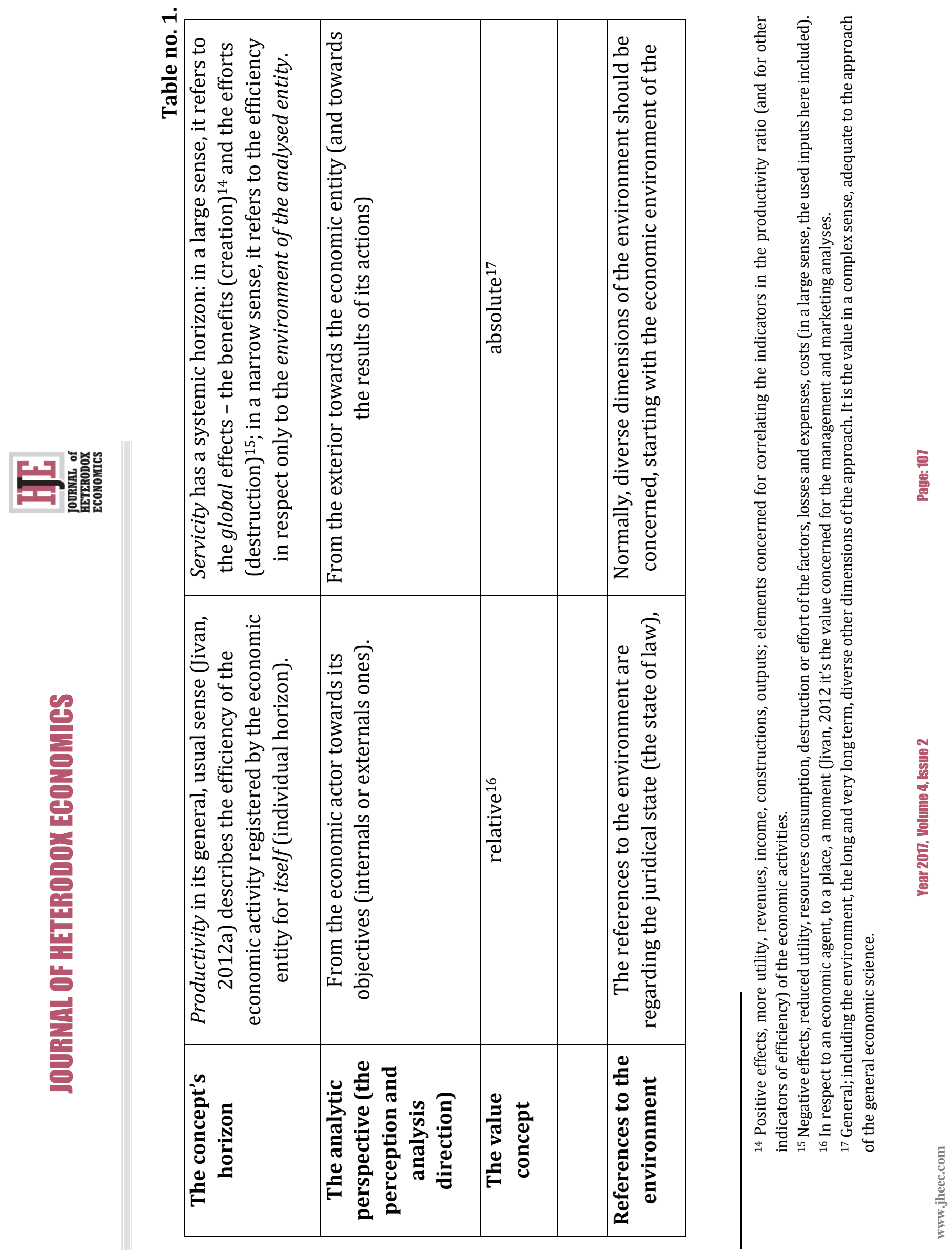




\begin{tabular}{|c|c|c|c|}
\hline & & & \\
\hline 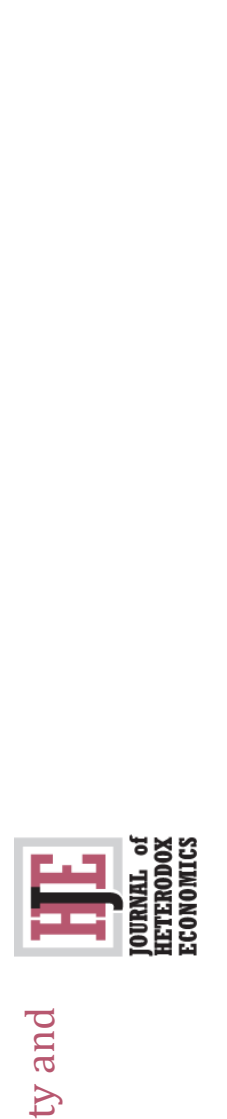 & 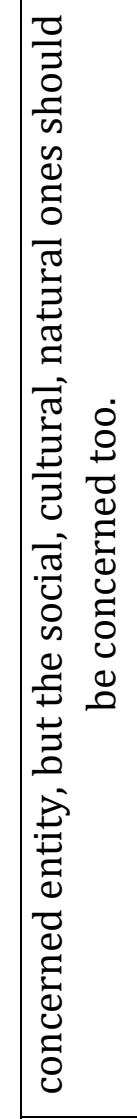 & 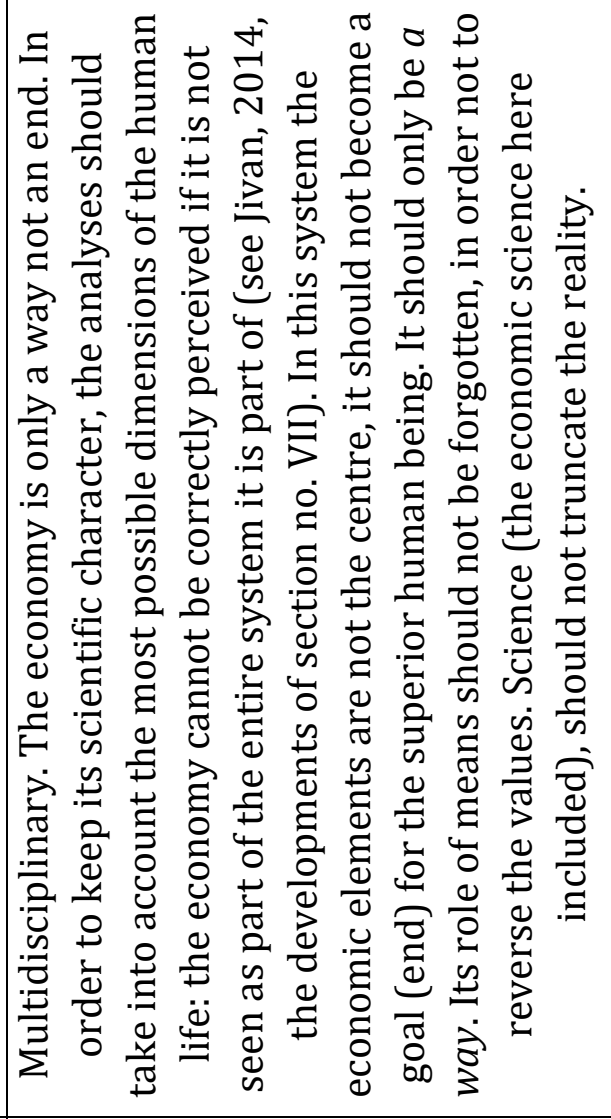 & 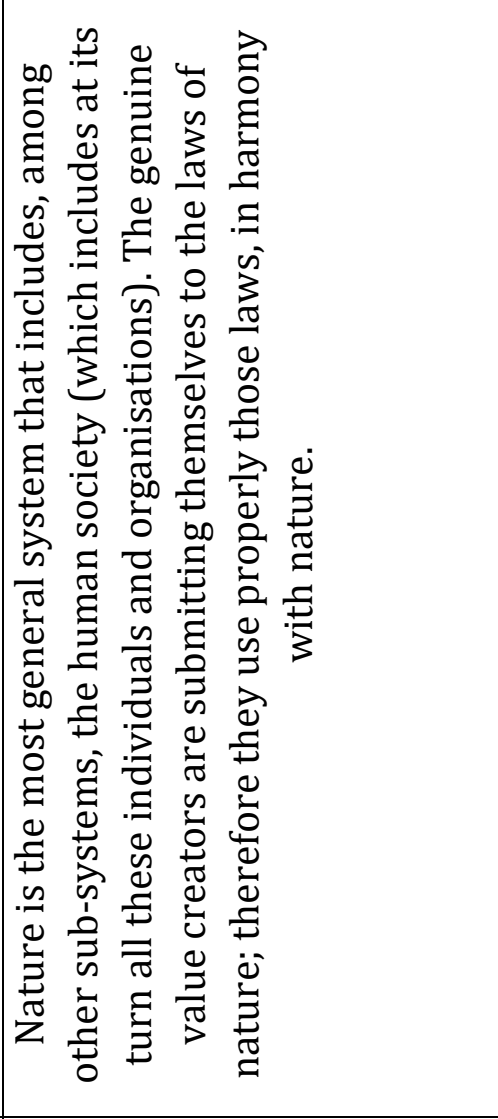 \\
\hline 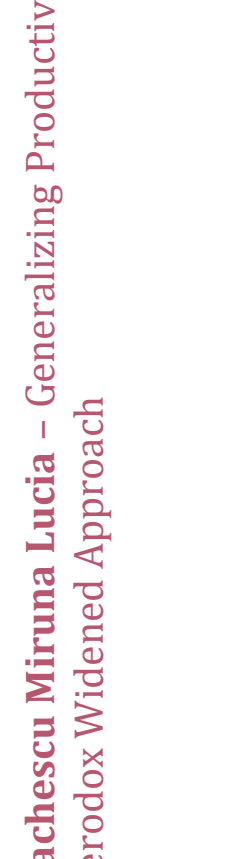 & 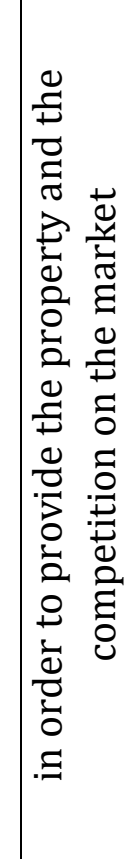 & 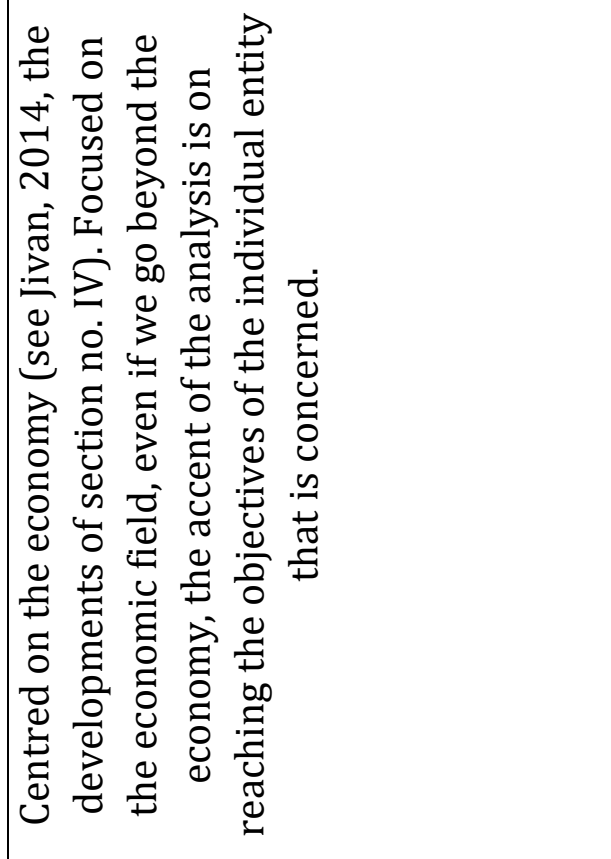 & 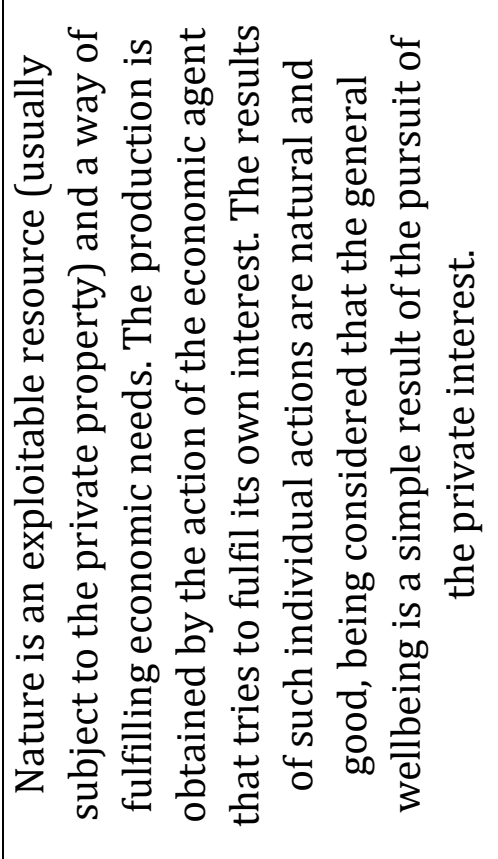 \\
\hline$\frac{\breve{s}}{J}$ & & 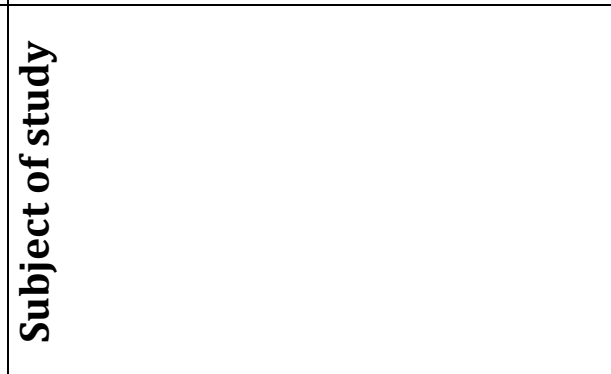 & 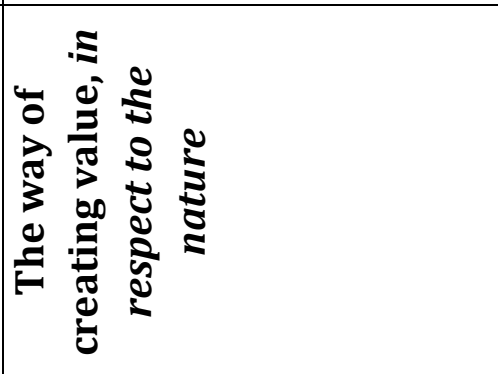 \\
\hline
\end{tabular}




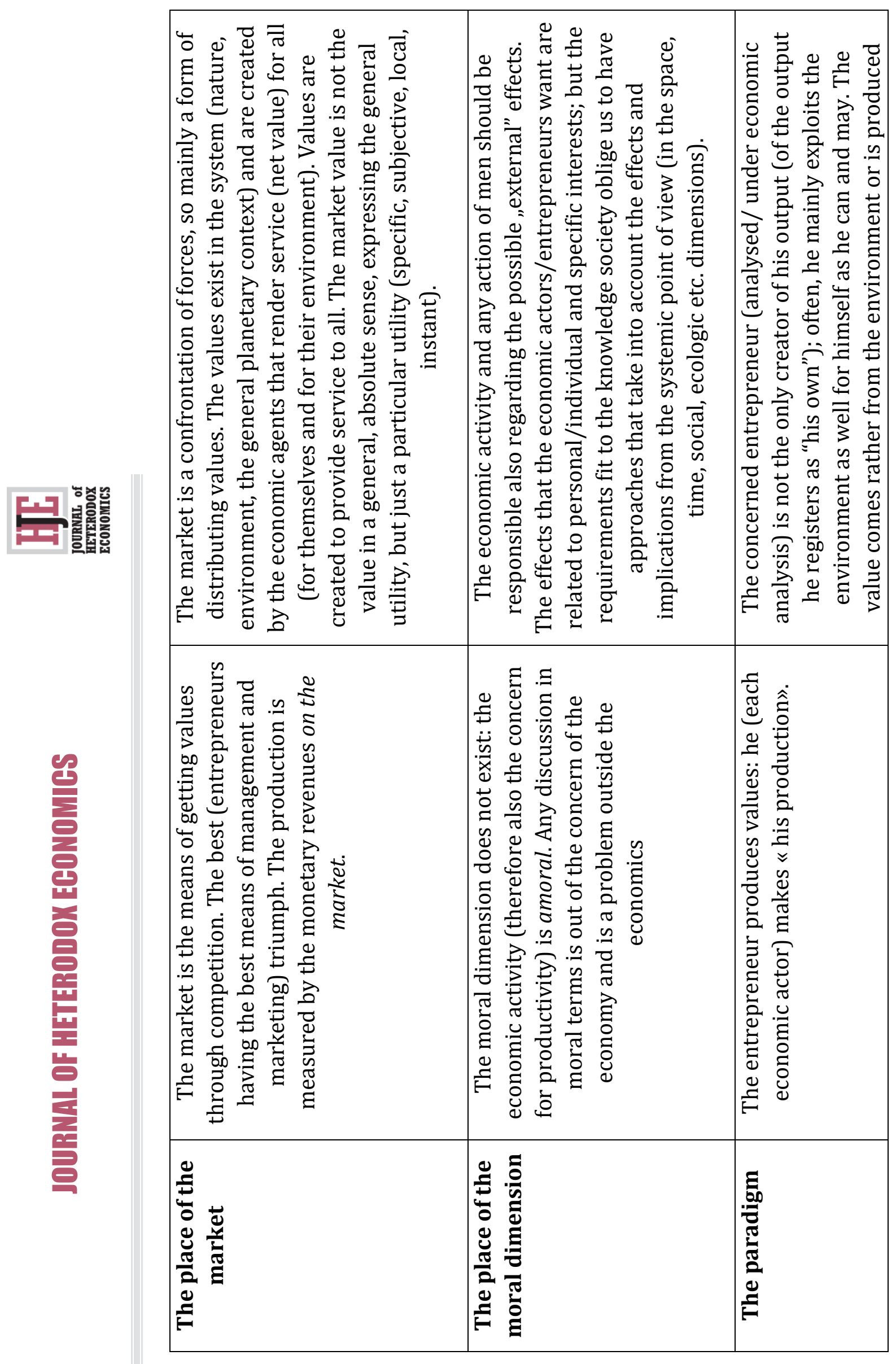




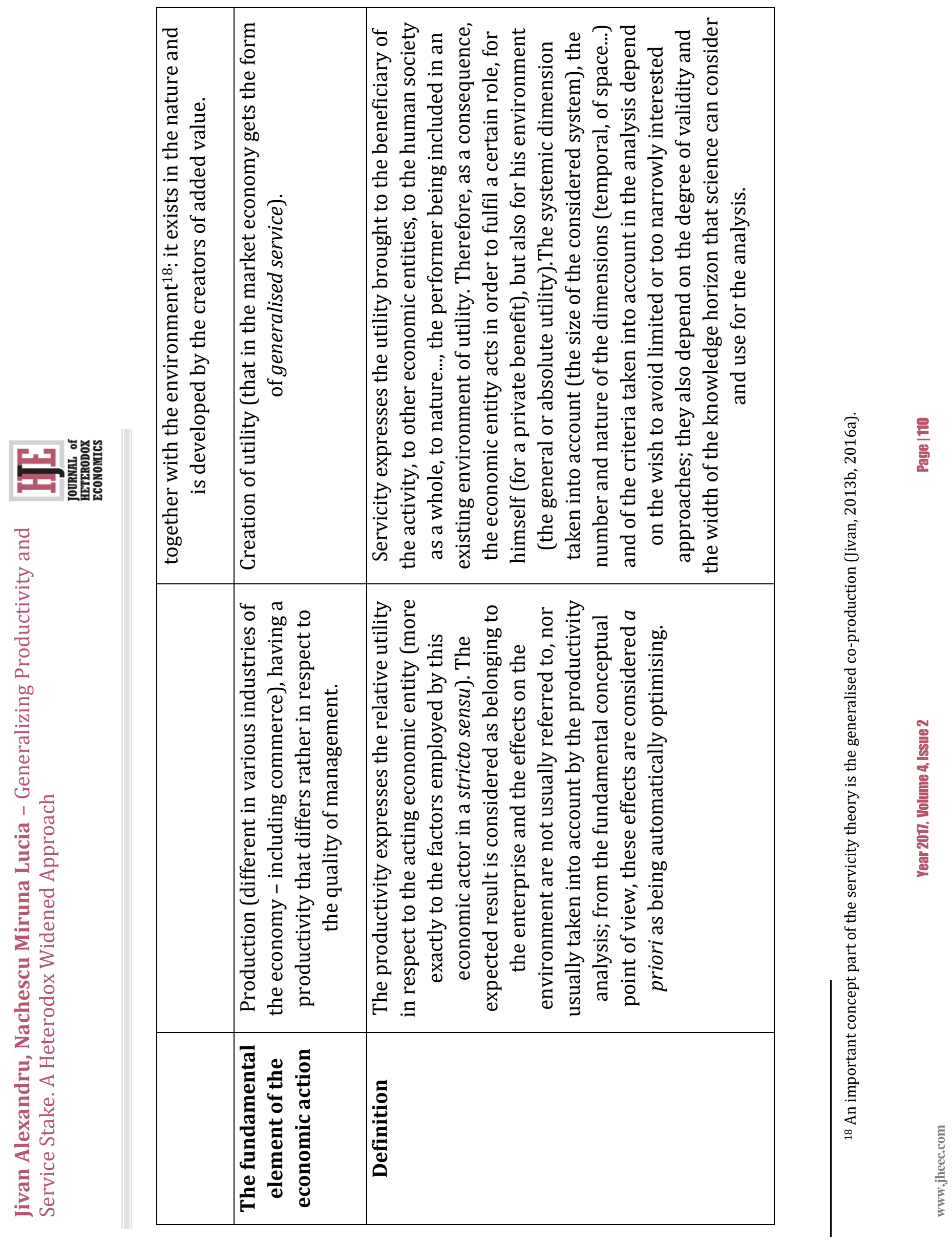




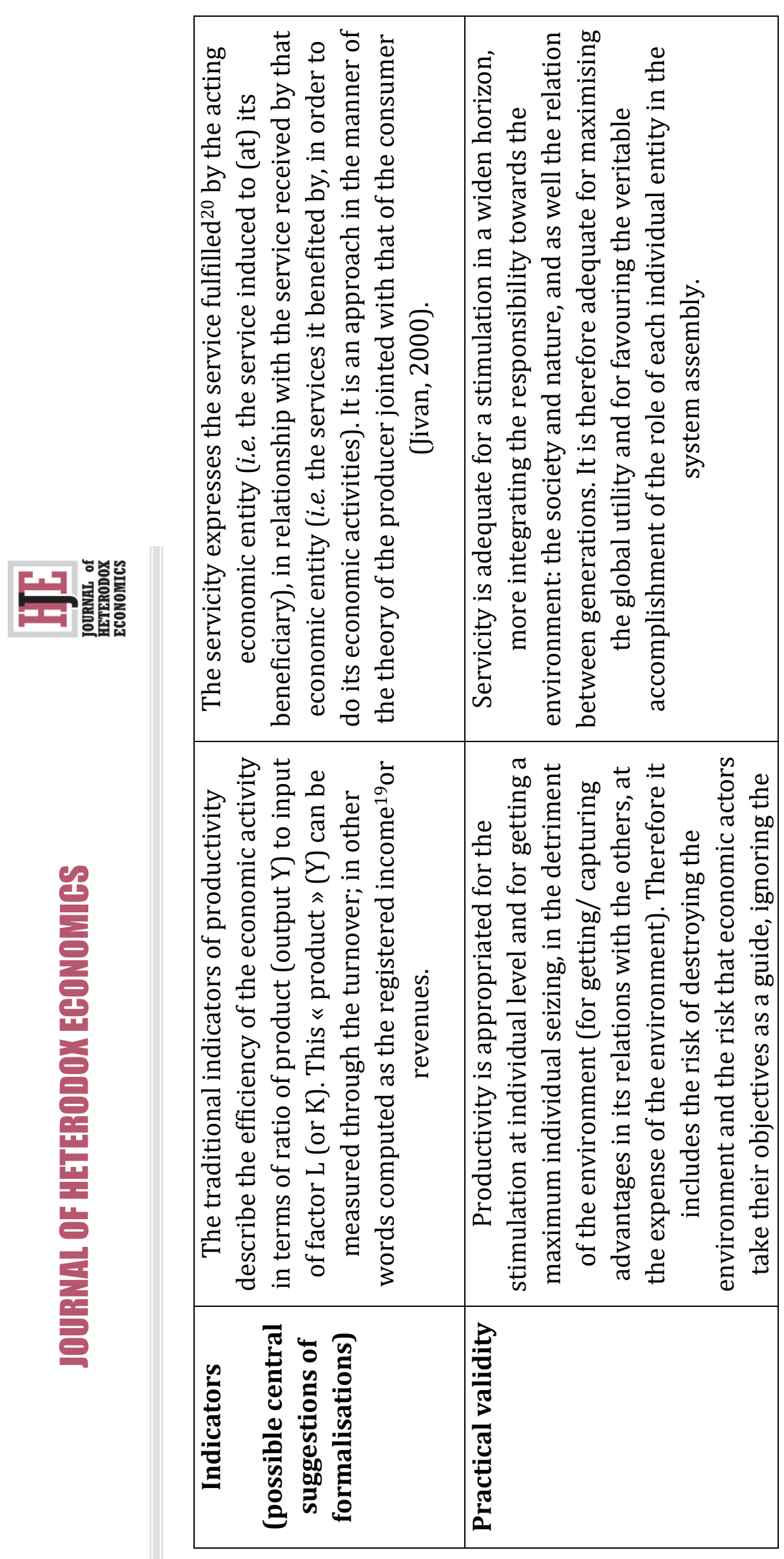

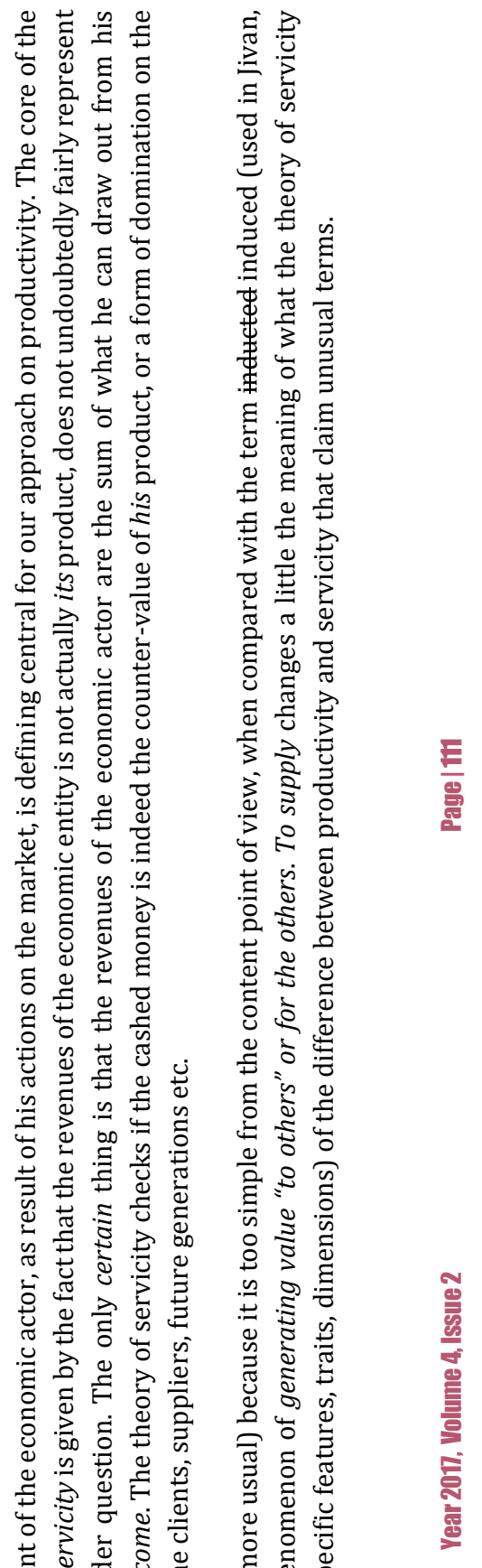

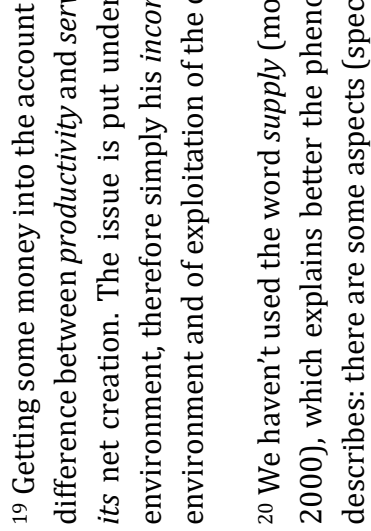

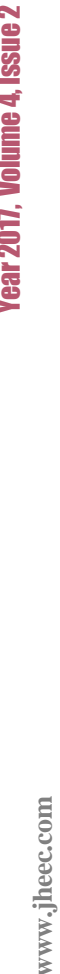



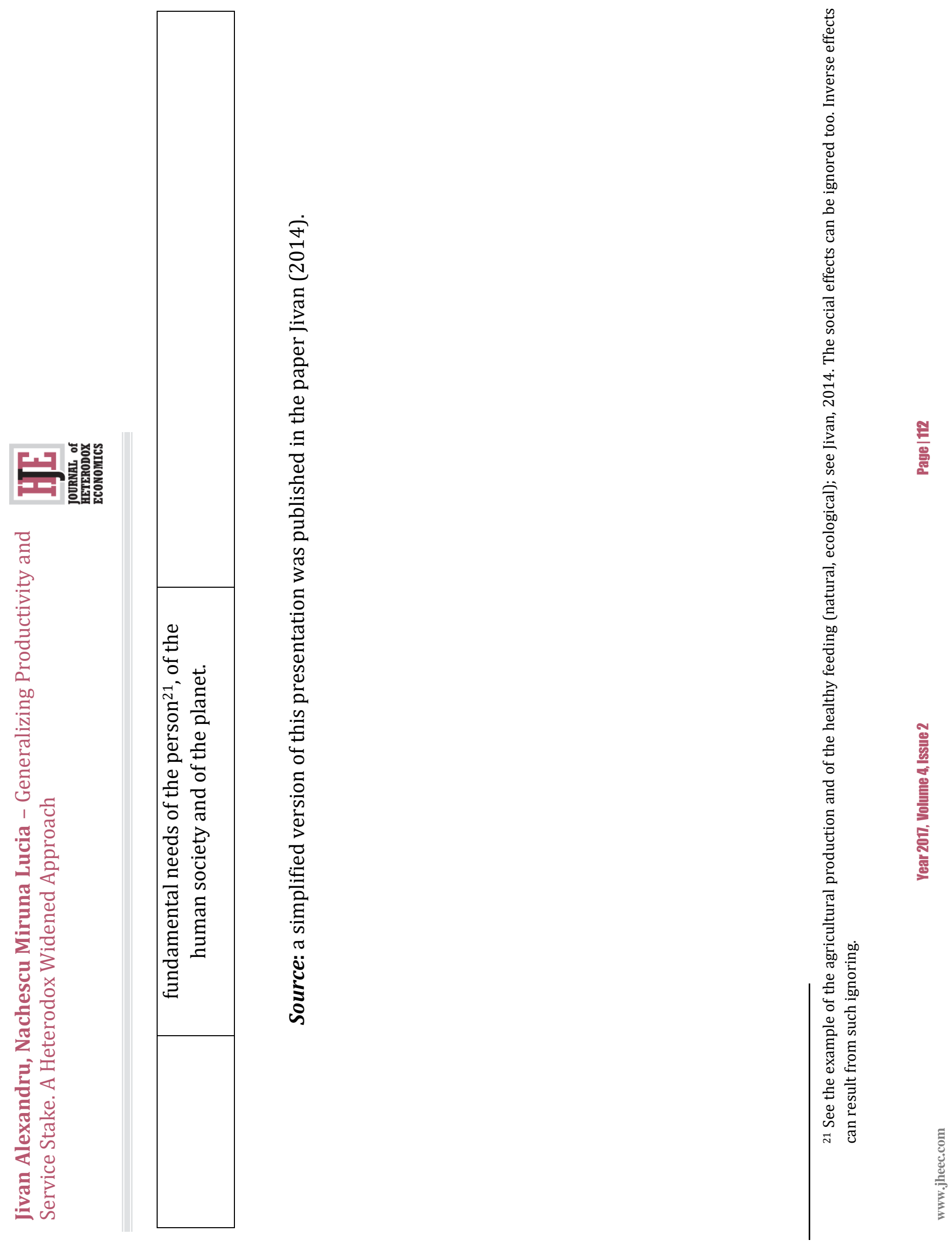


\section{Conclusions}

The present paper presents elements defining the servicity theory as alternative to productivity. The development of the theory in the last century and a half shows that, when the economic theory gives up certain conceptual principles (a few ideas from the genuine liberalism evoked in section no 2), adapting to the possibilities of the used methods (namely to the mathematic ones), one can reach the point where genuine value itself is ignored and the focus is just on price. Therefore, despite the distinction made by the classics, price got the role of value. We consider that knowledge society should allow widening the horizon that could include improvements of economic research, improvements that can be not only of nuance, but also fundamental/substantial.

As scientific foundation, we had firstly to invoke (i) the Physiocrats with their view concerning value creation, and (ii) certain most representative theorists of service economics: the general ground of our research was given by the genuine liberalism and by service economics, in the context of actual knowledge society. The conceptions about productivity that come from the period when the economic liberalism was born (conceived and developed) - i.e. the Physiocracy and Classical period (see the section no 2) - represent the starting point of a conception about productivity that was lost during the time, being not anymore found in the nowadays (Jivan, 2014).

Such logical principles grounded the approach of servicity (see the sections 3 and 4).

Opposite to the dominant economy (from marginalism/1871 towards today), the servicity approach comes back to the conceptual basis of the initial liberalism (at Quesnay, Smith and especially at Bastiat), which makes today the servicity approach heterodox. The design and settings in our paper provide a heterodox frame for models and analyses concerning servicity, in ways apart from the most usual ones (for commonly calculated productivity), alternatives that are more appropriate to the very inner meaning of value production (creation) that was conceived in the genuine liberalism.

If we take into account Nicholas Georgescu-Roegen's economic thinking (GeorgescuRoegen, 1979) and that of certain other thinkers from agricultural countries (countries which have other economic settings, levels and models of development than that of the most powerful economies), we could understand that, despite certain pretensions, the common (standard) model of economic life is, in fact, a particular, non-general one (Jivan, 2008 MM-NGR): the reality is perceived by certain patterns, in which each individual (scientists here included) perceive reality. Such particular approaches should be put under question and, thus, reviewed, improved, developed taking into account more widened horizons.

Background has been discussed in the sections, in accordance with the approaches to the issues of each section and with the specific presentation requirements within those 
sections, references being made only to (particularized) elements from the literature that can correspond to those issues.

This paper is analytical and conceptual. It acknowledges the limitation of being a definitory presentation of elements for the servicity analysis frame, without offering (in the present pages) clear formulas, particular or empirical applications. In the previous sections, we didn't have the intention to set well completed or final models, neither to give some final touches to such approaches, nor to apply them on particular real numbers from the economic practice. The developments in the previous sections just ground that an alternative apposite approach can be build and uphold (that such heterodox ways and models can be developed in the purpose of improving productivity practical meaning and calculation). Thus, the usual calculations concerning productivity can be made and developed in a widened horizon and completing the information provided by such analyses at diverse levels (enterprise, national and world economy).

The reason of our approach is that the strictly materialist economic approach and, thus, the common computing manner employed in practice and in theoretical analyses focused on production and productivity, alters the initial meanings (which it should have) of the productivity concept. This computation manner instigated to consumption at all costs, the planet's destruction, in the context of maintaining and increasing the social problems.

The context that urged to putting under question and discussing the common way of approaching and calculating productivity is today's economic life, the nowadays economy, the actual principle of basing the economic act and our whole society on knowledge. The analytical horizon must be broadened to the current levels of the general and in-depth knowledge. The present paper is an opening, a step in this direction.

The theoretical ideas we designed allow to be better seen a more completed picture of the reality, including parts of it that are often ignored by the most common analyses of productivity growth, claiming a broader horizon than the one usually considered.

The presentation was made by comparing the (i) common calculated productivity and the model or theory of the (ii) inner and generalised productivity of an economic entity or activity (servicity) as an alternative or a critical reaction to it. In this theoretical work, we highlighted the main defining features that design the distinction between productivity and servicity; in our paper we do not give yet a unique and simple way of measuring for the concept servicity as an expression of profound value generation. Further developments and tests can be done, after the openings we provide in the present paper; our proposals also opened future directions for developments and new research.

Conclusions reveal the relative character of the economic analyses, depending on the conceptual approach and the meaning assigned to the data. 
The conceptual conclusion coming from the already presented ideas and debate is that, in principle, the actually calculated indicator of productivity captures the concern for appropriation (absorption, acquisition) of values, from the environment, through market confrontations; but the creation of values (the inner productivity of actions and of entities) remains to the indicator of servicity (Jivan, 1993, 2014, and others). Servicity itself may be considered the conceptual improved result of the elements already presented.

Our proposals can be successfully integrated in the existing approaches, bringing completions and enriched explanations and interpretations (just if not always consistent with the most common ones) to the economic activities and to their effects, improving analyses, even by showing unnoticed features and unobserved sides of the complex reality.

Of course, the conceptual alternative we describe in the paper is not specifically designed to be applied immediately in current business analyses, even if some aspects are applicable; the approach of the paper is not mainly from a business point of view, but a general economics approach: the elements and aspects we concern are conceived rather for economics analyses in a wider horizon than usual. But the approach involves the possibility of new ways of understanding the market competition and suggesting directions and means of improved practices. Such practices refer firstly to general economics research and economic thought, but also in the field of business.

Nevertheless, in building marketing strategies, in that what concerns the accountingstatistical system of evidence (at the level of economic units as well, and also as a base for an improved approach of management in general), the elements presented in the paper are likely to raise the level of approaches to standards that could be more consistent with the essence of the knowledge economy. And such research steps, though not very common (even if unusual), would be beneficial to economic entities.

By employing a widened horizon of analysing their productivity and performance, industrial units could bring better constructive contribution in their environment and could gain improving image and position on the market.

\section{References}

Arrow, K. J. (1962), “The Economic Implication of Learning by Doing”, Review of Economic Studies 29, pp. 155-173, http://web.cenet.org.cn/upfile/12659.pdf, https://academic.oup.com/restud/article-abstract/29/3/155/1539235/The-EconomicImplications-of-Learning-by-Doing?redirectedFrom=PDF.

Barabasi A.-L. (2017) Linked: the New Science of Nets (in Romanian), Timișoara: Brumar. Bastiat, F. (1982), Harmonies économique, Libraires Guillaumin et Cie, Paris. 
Bossel, H. (1999), Indicators for Sustainable Development: Theory, Method, Applications. A Report to the Balaton Group, International Institute for Sustainable Development (IISD), Canada.

Caspar, P. and Afriat, Christine (1988), L'investissement intellectuel. Essai sur l'économie de l'immatériel, Éditions Economica, Paris.

Bell, D. (1999), The Coming of Post-Industrial Society. A venture in social forecasting, http://books.google.ro/books?id=q6_56x5tB7gC\&printsec=frontcover\&hl=ro\&source $=$ gbs_ge_summary_r\&cad $=0 \# \mathrm{v}=$ onepage $\& \mathrm{q} \& \mathrm{f}=$ false.

De Bandt, J. (1991) Les services, productivité et prix, Paris: Economica.

Delaunay J.-C., Gadrey J. (1987) Les enjeux de la societé de service, Presses de la Fondation Nationale des Sciences Politiques, Paris.

Drăgănescu, M. (1987), Informatica şi societatea, Ed. Politică, Bucureşti.

Eiglier, P. and Langeard E. (1988), Servuction. Le marketing des services. Coll. Strategie et management, Eds. Mc-Graw-Hill

Farell M. J. (1957), "The measurement of productive efficiency", Journal of the Royal Statistical Society (series A), 120 (3), 1957, p. 253-281]

Filip, F. G. (Ed.) (2001), Informational Society - Knowledge Society. Concepts, Solutions and Strategies for Romania, Expert Publishing House, Bucharest.

Fisher, A. G. B. (1935), The Clash of progress and Security, Macmillan, 1935.

Fourastié, J. (1963), Le grand espoir du XXe siècle, Éditions Gallimard, Paris.

Fuchs V. R. (1968), The Service Economy, National Bureau of Economic Research, General series nr. 87, New York.

Gadrey, J. (1992) L'économie des services, Paris: La Decouverte, Coll. Reperes.

Gadrey, J. (1996) Services: la productivité en question, Paris : Desclée de Brouwer.

Gadrey, J. and De Bandt, J. (1994) Relations de service, marchés de service, Paris: CNRS.

Gadrey, J. (2003), Socio-économie des services, Éditions La Découverte, Paris

Gallouj, F. and Weinstein, O. (1997) "Innovation in Services", Research Policy, vol. 26, n 45, p. 537-556.

Galvagno, M. and Dalli, D. (2014), "Theory of value co-creation: a systematic literature review", Managing Service Quality, 24 (6), 643 - 683

Georgescu-Roegen, N. (1979) The Law of Entropy and the Economic Process (in Romanian), Politica Publishing House, Bucharest.

Grönroos, C. (2008) "Service logic revisited: who creates value? And who co-creates?", European Business Review, Vol. 20 No. 4, pp. 298-314.

Hertog, P. den (2002), qoted in Gadrey, J. and Gallouj, F. (eds., 2002, p. 225)

Hill, P. (1977) "On Goods and Services", Review of Income and Wealth, 4(23), pp 315-338.

Jivan, A., 1993, "Services and Servicity", Services World Forum Bulletin, nr. 3,4/1993, Dublin, pag. 16-24

Jivan, A. (2008), „Possible Connection M. Manoilescu - N. Georgescu-Roegen, WellGrounded on the Knowledge Society", The International Conference Nicholas Georgescu-Roegen - 30 Years (1979-2008) of Roegenian Method (October 17-18 2008) 
Jivan, A. (2011) "Completions to Marshallian Out-Look, Consistent with Knowledge Based Economy”, Timişoara Journal of Economics (TJE), Vol. 4 Issue (nr.) 1(13), 2011 [31 mai 2011], p 11-18.

Jivan, A. (2013a) "Productivity as Registered Transfers Between Economic Entities. A Theoretical Intuitive Approach", Annals of The University of Oradea, Economic Sciences, ISSN 1582-5450 (electronic format), ISSN 1222-569X (printed format), 1st Issue/July 2013, The Tom XXII

Jivan, 2013b, Cybernetic Modelling CIBEREC, p. 154-170 "A systemic Approach on Productivity. Generalized Coproduction" in Proceedings of The Eight International Conference on Economic Cybernetic Analysis Development and Resources DERS2013, November 1-2, (CD) ISBN: 2247-1820; ISSN-L: 2247-1820, Bucharest, CIBEREC, The Bucharest University of Economic Studies, pp. 154-170

Jivan, A., (2015) "Les différences de servicité comme problème de compétitivité pour les pays émergeants”, Revue européenne du droit social, Volume XXVIII, ISSUE 3 ( $\left.\mathrm{n}^{\circ} 3\right)$, p. $156-171$

Jivan, A. (2016a) "Co-production in the servicity approach, on the grounds of Knowledge Economy", www.icbaer.ro, Analele University "Eftimie Murgu” Resita, p 116-123 (cfhttp://www.analefseauem.ro/upload/arhiva-revista/2016/Cuprins_2016.pdf

Jivan (coord. 2016b) Elements of Intellectual Services' Productivity, Mirton Publishing House, Timişoara.

Karpik, L. (1989), “L'économie de la qualitté”, Revue Française de sociologie, XXX2, pp. 197210, quoted in Djellal and Gallouj, 2008

Lengellé, Maurice(1966), La révolution tertiaire, Eds. Génin, Paris.

Levitt T. (1974) The Third Sector: New Tactics for a Responsive Society. New York: McGrawHill.

Manoilescu M. (1986). National Productive Forces and External Trade. Protectionism and International Exchange. Bucharest: Scientific and Encyclopaedic Printing House. [In Romanian].

Olson, M. (1972), 'Evaluating Performance in the service sector', in Moss, M. (ed.) The Measurement of Economic and social Performance, New York NBER: Columbia University Press.

2010 Ostrom, Amy L. et al. (2010) "Moving Forward and Making a Difference: Research Priorities for the Science of Service”, January 2010, Journal of Service Research 13(1):4-36, DOI: 0.1177/1094670509357611, in Galvagno, M. and Dalli D., (2014), "Theory of value co-creation: a systematic literature review", Managing Service Quality, 24 (6), $643-683$

Perroux, F. (1974), Pouvoir et economie, Dunod, Paris-Bruxelles-Montreal.

Pine, J. and Gilmore, J, (1999), The Experience Economy, Boston: Harvard Business School Press.

Revue d'Economie Industriele No 31/1985 (page 186)

Revue d'Economie Industrielle no. 43, 1988

Rittelli, D., Barbiroli, G. and Fabbri, P.(1997) "Predation among technologies on the market: a modellistic analysis", Journal of Mathematical Economics, 27:347-374. 
Sedlacek, Tomas (2012), Economia binelui şi a răului. În căutarea sensului economic, de la Ghilgameş la Wall Street. Editura Publica

Stahel W. (1997), 'The functional economy: cultural and organisational change', in Richards D.J. (Ed.) The Industrial Green Game: Implications for Environmental Design and Management. National Academy Press, Washington DC, p. 91-100.

Stiglitz, Joseph, Amartya Sen, Jean-Paul Fitoussi [2009], Vers de nouveaux systèmes de mesure, Maison d'Edition Odile Jacob, Paris.

Toffler, A. (1983), Al treilea val, Editura Politică, Bucureşti.

Vargo, S., and Lusch, R. (2004). "Evolving to a new dominant logic for marketing" Journal of Marketing, 68, 1-17

Vargo, S.L. and Lusch, R.F. (2008), "Service dominant logic: continuing the evolution", Journal of the Academy of Marketing Science, Vol. 36 No. 1, pp. 1-10. 